This is the peer reviewed version of the following article:

C. Pituello, N. Dal Ferro, O. Francioso, G. Simonetti, A. Berti, I. Piccoli, A. Pisi, F. Morari

Effects of biochar on the dynamics of aggregate stability in clay and sandy loam soils EUROPEAN JOURNAL OF SOIL SCIENCE Volume 69, Issue 5 September 2018 Pages 827-842

which has been published in final form at https://doi.org/10.1111/ejss.12676.

This article may be used for non-commercial purposes in accordance with Wiley Terms and Conditions for Use of Self-Archived Versions 


\title{
Effects of biochar on the dynamics of aggregate stability in clay and sandy loam soils
}

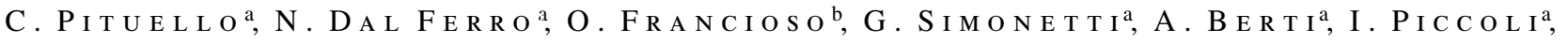 \\ A. P I S I ${ }^{\mathrm{b}} \& \mathrm{~F}$. M OR A R I ${ }^{\mathrm{a}}$ \\ a'Department of Agronomy, Food, Natural Resources, Animals and Environment, University of Padova, Viale Dell'Università 16, 35020 \\ Legnaro, Italy, and ${ }^{\mathrm{b} D e p a r t m e n t ~ o f ~ A g r i c u l t u r a l ~ a n d ~ F o o d ~ S c i e n c e s, ~ U n i v e r s i t y ~ o f ~ B o l o g n a, ~ V i a l e ~ F a n i n ~ 44, ~ 40127 ~ B o l o g n a, ~ I t a l y ~}$
}

\begin{abstract}
Summary
Recent advances suggest that organic substances of different origins might have different aggregate stability dynamics. We investigated the extent to which contrasting soil types affect the dynamics of aggregation after the addition of crop residues (R) and of biochar at two doses (BC20, 20 $\mathrm{Mgha}^{-1}$; $\mathrm{BC} 40,40 \mathrm{Mgha}^{-1}$ ) in a 2-year experiment. To evaluate disaggregation, we measured a set of physical-chemical and structure-related properties of clay and sandy loam aggregates sieved to $1-2 \mathrm{~mm}$, including wet aggregate stability after different pretreatments combined with laser diffraction analysis. The electrochemical properties of the colloidal suspension were also analysed to identify changes in soil chemistry affected by organic inputs. Different amounts of added biochar and soil types produced contrasting effects on wet aggregate stability. In sandy loam, the increased soil surface area from added biochar (at either dose) offset the initial small soil organic carbon (SOC) content and subsequently promoted SOC-controlled aggregation. Conversely in clay soil, the larger biochar dose (BC40) strengthened the repulsive forces between particles with the same charge and monovalent cations, which led to chemical perturbation and some aggregate breakdown not found with $\mathrm{BC} 20$. Pore structure also changed in clay aggregates. A shift towards more micropores $(30-5 \mu \mathrm{m},+29 \%$ more than in the control) and ultramicropores $(5-0.1 \mu \mathrm{m},+22 \%$ more than in the control), which contributed to aggregate stabilization, resulted when biochar was added, but not for residue. Our results suggest that biochar promotes aggregate stability, which, in turn, improves the physical fertility of soil, especially if it has a coarse texture and small organic carbon content. Further study is needed of the physical-chemical interactions between added biochar and surface-charged clay-rich soils.
\end{abstract}

\section{Highlights}

- Aggregate dynamics are poorly understood because of complex interactions between organic inputs and soil type.

- A multidisciplinary approach was used to study aggregation dynamics.

- Large biochar input changed soil chemical properties that weakened stability in clay aggregates.

- Aggregate stability depended on biochar dose and soil type.

\section{Introduction}

The relation between soil organic carbon (SOC) and aggregate stability has been well studied given the important roles SOC plays in soil fertility and carbon sequestration. Six \& Paustian (2014) have indicated that the key factors of SOC function and turnover are location of organic matter within the soil matrix

Correspondence: N. Dal Ferro. E-mail: nicola.dalferro@unipd.it and characteristics of the organic-mineral complex. However, the importance of the interaction between SOC and soil structure at different spatiotemporal scales remains elusive. Research has recently advanced the idea that spatial arrangement within the mineral soil matrix, as well as interactions at the scale of the redox environment and microbes (Lehmann \& Kleber, 2015), affects the rate of SOC decomposition (Schmidt et al., 2011). Nevertheless, the major factors of aggregate stability, the structure of organic matter in carbon-based compounds and its inherent capacity to bind soil, require better understanding. 
Soil organic carbon is known to reduce soil vulnerability to both slaking and physical-chemical dispersion (Le Bissonnais, 1996) through several mechanisms: (i) by forming a hydrophobic film around soil particles that slows wetting, (ii) by increasing interparticle cohesion (Bachmann et al., 2008) and (iii) by reducing internal air pressure and consequent aggregate disruption through modification of pore spaces (Dal Ferro et al., 2012). Various forms of organic carbon are already commonly applied as amendments by farm operators. Crop residues, when used as a soil amendment, generally improve the physical properties of a soil (Powlson et al., 2011): aggregate stability, water infiltration and plough draft, bulk density and total porosity. Biochar, a promising soil amendment, might not only affect aggregate stability, but might also favour soil carbon sequestration and mitigate climate change (Lehmann \& Kleber, 2015).

The effects of biochar stem primarily from its physical characteristics (large porosity and surface area), which vary depending on pyrolytic parameters and feedstock characteristics (Pituello et al., 2015). By adding biochar, basic soil properties (e.g. bulk density, soil water retention) are positively affected (Yu et al., 2016). Debate continues on the use of biochar to increase soil particle aggregation (Schmidt et al., 2011) because the range of feedstocks and technologies used for its production make it difficult to draw conclusions (Blanco-Canqui, 2017). Moreover, biochar affects texture and SOC content, which, in turn, can increase or decrease wet aggregate stability.

Some studies have reported positive effects from biochar produced at high temperatures on aggregate stability in clay and silty clay soils (e.g. Sun \& Lu, 2014). Peng et al. (2011) found low-temperature rice-straw biochar increased soil aggregation in clay loam soil. Contrasting results for different biochars have been observed in sandy loam soils. For instance, the addition of high temperature-derived biochar enhanced macroaggregate formation (Ouyang et al., 2013), whereas other biochars compromised aggregate stability (Ojeda et al., 2015). Interestingly, Kumari et al. (2017) observed that dispersibility of soil colloids rose with increasing rates of biochar application because biochar induced changes in the electrochemical properties of the dispersed colloids (e.g.electrical conductivity), which reduced soil particle aggregation. Worthy of note is that most published studies have been carried out under controlled laboratory conditions; only a few (e.g. Kumari et al., 2017) have been carried out in the field.

The inconclusive nature of results warrants further examination of the effects of biochar incorporation on soil aggregation under conditions representative of natural environments. Specifically, a comparison of biochar with conventional amendments used to improve wet aggregate stability is needed. Therefore, we hypothesize that soil aggregate dynamics are affected by both organic inputs and the physical-chemical interactions of soil properties that act to breakdown the aggregate, rather than to stabilize it. This study had two objectives: (i) to evaluate the effects of crop residues and two amounts of biochar addition (20 and $40 \mathrm{Mg} \mathrm{ha}^{-1}$ ) on soil aggregate structure (i.e. porosity and stability) and (ii) to investigate the extent to which soil type affects organic compound residue-mediated and biochar-mediated aggregation dynamics.

\section{Material and methods}

\section{Long-term experimental design: 1970 to 2012}

A long-term field experiment was established in 1970 at the experimental farm 'L. Toniolo' of the University of Padova $\left(45^{\circ} 21^{\prime} \mathrm{N}\right.$, $11^{\circ} 50^{\prime} \mathrm{E} ; 6 \mathrm{~m}$ a.s.l.). The local climate is sub-humid with a mean annual rainfall of $825 \mathrm{~mm}$. The temperature reaches minimum values in January $\left(2.3^{\circ} \mathrm{C}\right.$, on average) and maximum values in July and August $\left(22.4^{\circ} \mathrm{C}\right.$, on average). Reference evapotranspiration $\left(\mathrm{ET}_{0}\right)$ is $945 \mathrm{~mm} \mathrm{y}^{-1}$, which exceeds the April to September rainfall (maximum peak in July, $5 \mathrm{~mm} \mathrm{day}^{-1}$ ). The site has a shallow water table that ranges from about $0.5-1.5 \mathrm{~m}$ (from late winter to early spring) to $1-2 \mathrm{~m}$ (in summer).

Initially, 108 lysimeters $\left(4 \mathrm{~m}^{2}, 80-\mathrm{cm}\right.$ deep $)$ and three types of soils (clay, sandy loam and sandy) were used to study the effects of high- and low-input cropping systems. The clay soil is classified as a Gleyic-Vertic Chernozem, the sandy loam soil as a Fluvi-Calcaric Cambisol and the sandy soil as a Calcaric Arenosol (FAO-UNESCO, 2008). Until 1988, the trial was conducted with a maize-wheat rotation, comparing 12 treatments as a factorial combination of three nitrogen applications (from 0 to $200 \mathrm{~kg} \mathrm{ha}^{-1}$ ) and four crop residue managements (burial or removal of one or both crops). The trial was modified in 1988 to a 4-year rotation of wheat-maize-tomato or potato-sugarbeet. Crop residue management was simplified to compare two situations (burial or removal), whereas the nitrogen applications considered were increased to six (from 0 to $400 \mathrm{~kg} \mathrm{ha}^{-1}$ ). These treatments were maintained until the end of the experiment in 2012. Further details are given in Pituello et al. (2016a).

\section{Modification of experimental design to evaluate effects of carbon inputs on soil properties: 2013}

In 2013, the experimental treatments were modified to evaluate the effects of different carbon sources on soil properties. The experimental design was a randomized block with three replicates. Treatments were defined by the factorial combination of four carbon management inputs and three nitrogen fertilization amounts, with maintenance of the 4-year rotation. Carbon management included three types: (i) a control (NR) with no crop residue incorporation or biochar addition, (ii) incorporation of crop residues from the previous year (R), ranging in annual amounts (dry matter) from 4.69 to $9.09 \mathrm{Mg} \mathrm{ha}^{-1}$ in clay, 4.00 to $7.86 \mathrm{Mg} \mathrm{ha}^{-1}$ in sandy loam and 1.73 to $5.73 \mathrm{Mg} \mathrm{ha}^{-1}$ in sandy soil (Pituello et al., 2016b), and (iii) one-time biochar application of $20 \mathrm{Mg} \mathrm{ha}^{-1}$ (BC20) and one-time biochar application of $40 \mathrm{Mg} \mathrm{ha}^{-1}$ (BC40). Amounts of $\mathrm{N}$ fertilizer were 0,100 and $300 \mathrm{~kg} \mathrm{~N} \mathrm{ha}^{-1}$ year $^{-1}$. Biochar was applied once in December 2013 and incorporated by shovel into the top 20-cm layer. The two rates corresponded to approximately 13.7 and $27.4 \mathrm{Mg} \mathrm{C}$ $\mathrm{ha}^{-1}$, which corresponded to about $44 \%$ and $88 \%$ of the native soil organic carbon (SOC) for the clay soil, $67 \%$ and $133 \%$ for the sandy 
Table 1 Main physical and chemical properties of the soils at the start of the experiment (1970)

\begin{tabular}{|c|c|c|}
\hline Property & Clay & Sandy loam \\
\hline Sand $(2-0.05 \mathrm{~mm}) / \%$ & 40.6 & 57.1 \\
\hline Silt $(0.05-0.002 \mathrm{~mm}) / \%$ & 18.0 & 23.7 \\
\hline Clay $(<0.002 \mathrm{~mm}) / \%$ & 41.4 & 19.2 \\
\hline $\mathrm{pH}\left(\mathrm{H}_{2} \mathrm{O}\right)$ & 7.7 & 7.8 \\
\hline $\mathrm{SOC}^{\mathrm{a}} / \%$ & 1.06 & 0.62 \\
\hline Total $\mathrm{CaCO}_{3} / \%$ & 6.2 & 30.8 \\
\hline $\mathrm{P}_{2} \mathrm{O}_{5}$ labile $/ \mathrm{g} \mathrm{kg}^{-1}$ & 5.29 & 1.24 \\
\hline $\mathrm{P}_{2} \mathrm{O}_{5}$ ass. ${ }^{\mathrm{b}} / \mathrm{mg} \mathrm{kg}^{-1}$ & 59.0 & 23.0 \\
\hline $\mathrm{K}_{2} \mathrm{O}$ exc. $.^{\mathrm{c}} / \mathrm{mg} \mathrm{kg}^{-1}$ & 1.1 & 4.6 \\
\hline $\mathrm{N}$ tot $/ \mathrm{g} \mathrm{kg}^{-1}$ & 1.7 & 0.9 \\
\hline
\end{tabular}

a Rotini method.

${ }^{\mathrm{b}}$ Ferrari method

${ }^{\mathrm{c}}$ Exchangeable $\mathrm{K}_{2} \mathrm{O}$ with $25 \% \mathrm{NaNO}_{3}$ pretreatment.

loam soil, and seven- and 14-fold for the sandy soil, respectively. Maize (Zea mays L.) was cultivated in 2014 and 2015, and fertilized with an additional $150 \mathrm{~kg} \mathrm{ha}^{-1}$ year ${ }^{-1} \mathrm{P}_{2} \mathrm{O}_{5}$ and $200 \mathrm{~kg} \mathrm{ha}^{-1}$ year $^{-1}$ $\mathrm{K}_{2} \mathrm{O}$ during sowing.

In this study, soil structure and structure-related properties were analysed for two of three soil types (clay and sandy loam) because sandy soil did not show any sort of particle aggregation (Table 1). Four carbon management practices were included in the analysis as follows: NR, with no crop residue incorporation, biochar addition or mineral fertilizer (control), whereas the following management practices were fertilized with $300 \mathrm{~kg} \mathrm{~N} \mathrm{ha}^{-1}$ year $^{-1}: \mathrm{R}$, yearly incorporation of crop residues, $\mathrm{BC} 20$, biochar addition of $20 \mathrm{Mg} \mathrm{ha}^{-1}$ and $\mathrm{BC} 40$, biochar addition of $40 \mathrm{Mg} \mathrm{ha}^{-1}$.

\section{Analysis of biochar properties}

As described above, two amounts of biochar were used in the experiment to assess the effects of carbon input on aggregate stability and structure. We used biochar produced from wood residue pyrolysed at $800^{\circ} \mathrm{C}$ in a gasification plant. The particle size was very heterogeneous; it comprised a macroscopic fraction with particles of 2-4 $\mathrm{mm}$ and a powdery fraction with particles less than $2 \mathrm{~mm}$. A Mastersizer 2000 laser diffraction granulometer (Malvern, Instruments Ltd, Malvern, UK) was used to determine the mean particle diameter of the mesh-sieved powdery biochar fraction $(8.79 \mu \mathrm{m}$ across a range from 1 to $800 \mu \mathrm{m})$. The specific surface area, measured by $\mathrm{N}_{2}$ adsorption with a Sorptomatic 1990 (Thermo Fisher Scientific, Inc., Waltham, MA, USA), was $13.78 \mathrm{~m}^{2} \mathrm{~g}^{-1}$, with a pore volume (diameter range, $0.025-5 \mathrm{~nm}$ ) of $0.04 \mathrm{~cm}^{3} \mathrm{~g}^{-1}$. Total $\mathrm{C}$ and $\mathrm{N}$ contents, 686 and $4.0 \mathrm{~g} \mathrm{~kg}^{-1}$, respectively, were determined by combustion with an Elementar varioMACRO apparatus (Elementar Americas, Inc., Mt. Laurel, NJ, USA) after sieving at $500 \mu \mathrm{m}$. The $\mathrm{pH}$ (8.4) and electrical conductivity (EC) $\left(473 \mu \mathrm{S} \mathrm{cm}^{-1}\right)$ of biochar (sieved at $2 \mathrm{~mm}$ ) were measured in a 1:20 biochar-to-water suspension after shaking at 70 revolutions minute ${ }^{-1}$ for 1 hour. Cation exchange capacity (CEC), based on the ammonium acetate method,
Table 2 Main physical and chemical characteristics of the biochar applied

\begin{tabular}{lc}
\hline Property & Value \\
\hline $\mathrm{pH}$ & 8.43 \\
$\mathrm{EC} / \mathrm{dS} \mathrm{m}^{-1}$ & 473.0 \\
$\mathrm{CEC} / \mathrm{cmol}_{\mathrm{c}} \mathrm{kg}^{-1}$ & 2.3 \\
$\mathrm{C} / \mathrm{g} \mathrm{kg}^{-1}$ & 686.0 \\
$\mathrm{~N} / \mathrm{g} \mathrm{kg}^{-1}$ & 4.0 \\
$\mathrm{P} / \mathrm{g} \mathrm{kg}^{-1}$ & 1.1 \\
$\mathrm{Na} / \mathrm{g} \mathrm{kg}^{-1}$ & 1.01 \\
$\mathrm{~K} / \mathrm{g} \mathrm{kg}^{-1}$ & 11.8 \\
$\mathrm{Ca} / \mathrm{g} \mathrm{kg}^{-1}$ & 26.6 \\
$\mathrm{Mg} / \mathrm{g} \mathrm{kg}^{-1}$ & 3.2 \\
$\mathrm{SSA} / \mathrm{m}^{2} \mathrm{~g}^{-1}$ & 13.78 \\
\hline
\end{tabular}

${ }^{\text {a } S S A, ~ s p e c i f i c ~ s u r f a c e ~ a r e a . ~}$

was $2.3 \mathrm{cmol}_{\mathrm{c}} \mathrm{kg}^{-1}$. A Zetasizer Nanoseries (Malvern Instruments, Malvern, UK) was used on pure biochar to measure the zeta potential $(\zeta \mathrm{n})$ as $-27.7 \mathrm{mV}$, which indicated it carried a negative charge on its surface. Additional biochar characteristics are reported in Table 2.

\section{Soil sampling}

Soil sampling was carried out in June 2015. Samples were collected from three different points at $0-20-\mathrm{cm}$ depth of each lysimeter by auger (diameter of $7 \mathrm{~cm}$ ), and then bulked to obtain a sample of approximately $1 \mathrm{~kg}$. Samples were gently broken along natural fissures, air-dried and sieved to produce aggregates of between 1 and $2 \mathrm{~mm}$ in size.

\section{Physical-chemical analyses of soil aggregates}

To investigate the effect of various carbon treatments (NR, without mineral fertilizer (control), and $\mathrm{R}, \mathrm{BC} 20$ and $\mathrm{BC} 40$ fertilized with $300 \mathrm{~kg} \mathrm{Nha}^{-1} \mathrm{y}^{-1}$ ) on the aggregate structure and stability of clay and sandy loam soils (Table 1), many physical and chemical analyses were conducted as described below.

Soil aggregate organic carbon content and pore-size distribution. Soil aggregates were analysed for SOC content by dichromate oxidation (Walkley \& Black, 1934). Topsoil (0-20 cm) SOC stock was calculated in such a way that it accounted for SOC content and bulk density (data previously published in Pituello et al., 2016b), according to the depth of biochar incorporation.

Accessible porosity and pore-size distribution in the range of $0.0074-100-\mu \mathrm{m}$ diameter were measured by two mercury intrusion porosimetry devices (Thermo Fisher Scientific, Inc.), named Pascal $140(3.8-100 \mu \mathrm{m})$ and Pascal $240(0.0074-15 \mu \mathrm{m})$. Pore radius $(R)$ was calculated with the Young-Laplace equation:

$$
R=\frac{2 \gamma \cos \theta}{P}
$$

where $\gamma$ is the surface tension of pure mercury, $\theta$ is the contact angle $\left(140^{\circ}\right)$ between mercury and the sample and $P$ is the pressure. 
Pores were classified according to Cameron \& Buchan (2006) as: cryptopores $(0.0074-0.1 \mu \mathrm{m})$, ultramicropores $(0.1-5 \mu \mathrm{m})$, micropores $(5-30 \mu \mathrm{m})$, mesopores $(30-75 \mu \mathrm{m})$ and macropores $(75-100 \mu \mathrm{m})$.

Capillary rise method and estimate of contact angle. Hydrophobicity was determined by advancing contact angle (CA) with the capillary rise method, which measures differences in the rise of water and ethanol inside columns of soil. To do so, soil aggregates were carefully introduced into hydrophobic (paraffin wax coated) glass tubes $(52-\mathrm{cm}$ high $\times 1-\mathrm{cm}$ diameter $)$ with a filter at the base. To equate the bulk densities, the columns were filled with identical masses of soil and tapped to achieve identical heights. Two columns were filled with the same soil material; one was immersed in water while the other was in ethanol for 2 hours. Thereafter, the column liquid heights were measured and the contact angle was determined using the following equation (Siebold et al., 1997):

$$
h^{2}+2 h L=\frac{r \gamma_{\mathrm{F}} \cos \theta}{2 \eta} \mathrm{t}
$$

where $h$ is the height of the liquid inside the soil column, $L$ is the level of immersion of the column inside the liquid supply tank, $r$ is the capillary radius, $\gamma_{\mathrm{F}}$ is the fluid surface tension, $\theta$ is the contact angle, $\eta$ is fluid viscosity and $t$ is time. The ethanol contact angle was assumed to be zero, whereas that of water was characterized by the soil-liquid hydrophobic interface. The capillary radius remains constant; therefore, the soil-water contact angle can be calculated by combining Equation (2) for ethanol and water. A larger estimated angle indicates more pronounced hydrophobicity.

Aggregate morphology. An automated particle characterization system (Morphologi G3, Malvern Instruments Ltd, Malvern, UK) was used to determine aggregate mean diameter and morphologic properties. The instrument produced a detailed analysis by automatically capturing images of the sample scanned with microscopic optics. Prior to analysis, aggregates were dispersed manually on to a glass plate and carefully separated with a small brush to avoid their contact. The instrument was set to operate according to a procedure specifically selected for the samples under analysis. The optics were set as follows: $2.5 \times$ magnification objective with an episcopic light mode and an exposure of $100 \mathrm{~ms}$, enhanced with automated 'particle stitching' to recognize aggregates occupying two or more frames that could be 'stitched' together to extract the entire 'edge-stitched' aggregate. Particles outside the 1-2-mm diameter range were excluded from analysis. The threshold and focus were set manually before each measurement. A minimum of 50 aggregates were analysed for each sample. Aggregate mean diameter was calculated as the equivalent circle diameter (ECD) (i.e. the diameter of a circle with the same area (A) of the two-dimensional image of the object) according to the equation below and reported in Table 3:

$$
\mathrm{ECD}=2 \sqrt{\frac{A}{\pi}}
$$

Circularity $(C)$, a measure of how well an object approximates a perfect circle, was calculated as follows:

$$
C=\frac{2 \pi A}{P^{2}},
$$

where $A$ is the particle area and $P$ is the particle perimeter. Circularity ranged between 0 and 1 , where 1 corresponds to a perfect circle, whereas irregular objects approached 0 .

Convexity $\left(C_{\mathrm{x}}\right)$ measures the edge roughness of a particle, and is the ratio between the convex hull perimeter $\left(P_{\mathrm{c}}\right)$ and the actual perimeter of an object:

$$
C_{\mathrm{x}}=\frac{P_{\mathrm{c}}}{P} .
$$

Convexity ranged between 0 and 1 . An object with a convexity of 1 indicates a smooth shape because the convex hull perimeter equals the actual perimeter.

Solidity $(S)$, a measure of the overall concavity of a particle, is obtained as the ratio between the area of the object and the area enclosed by the convex hull $\left(A_{\mathrm{c}}\right)$ :

$$
S=\frac{A}{A_{c}} .
$$

Solidity values also range between 0 and 1 . A more solid object produces a more similar image and convex hull areas, and results in a solidity value that approaches 1 . The elongation index $\left(E_{\mathrm{i}}\right)$, a measure of the overall symmetry or asymmetry of an object, is determined by:

$$
E_{\mathrm{i}}=1-\frac{\text { width }}{\text { length }}
$$

where width and length are the shortest and longest object axes, respectively. Elongation indicates the symmetry (close to 0) or asymmetry (close to 1 ) of an object in all directions.

Scanning electron microscope (SEM) images. Images for NR and $\mathrm{BC} 40$ treatments of clay and sandy loam soils were scanned with a Philips SEM 515 electron microscope (Philips, Eindhoven, the Netherlands). Dry samples were mounted on aluminium stubs with silver glue and coated with gold-palladium film with an ion-sputtering unit Balzer MED 010 (Balzers Union Ltd, Balzers, Liechtenstein), and observed at $7 \mathrm{kV}$. Images were taken with a Nikon 5400 Coolpix digital camera (Nikon, Chiyoda-ku, Tokyo).

Electrochemical properties of dispersed colloids. About $30 \mathrm{~g}$ of soil aggregates were reserved to determine the electrochemical properties of the water-dispersible colloids, whose stability suggests that colloids remain suspended without sedimentation or flocculation (Seta \& Karathanasis, 1997). Before dispersion, aggregates were subjected to different pretreatments and fast wetting for the aggregate stability measurements (see paragraph below for details). After pretreatment, a similar procedure to that of Kumari et al. (2017) was used to disperse the soil aggregates in a sedimentation bottle with deionized water until a soil : water ratio of 1:8 by weight was achieved. The soil aggregates were dispersed manually by rotating the bottles 10 times in $50 \mathrm{~s}$, and then they 
Table 3 Examples of various particles and shape-related parameters

\begin{tabular}{|c|c|c|c|c|}
\hline Particle shape & $\begin{array}{l}\text { Circularity } \\
C=\frac{2 \pi A}{P^{2}}\end{array}$ & $\begin{array}{l}\text { Convexity } \\
C_{\mathrm{x}}=\frac{P_{\mathrm{c}}}{P}\end{array}$ & $\begin{array}{l}\text { Solidity } \\
S=\frac{A}{A} \mathrm{c}\end{array}$ & $\begin{array}{l}\text { Elongation index } \\
E_{\mathrm{i}}=1-\frac{\text { width }}{\text { length }}\end{array}$ \\
\hline & 1.00 & 1.00 & 1.00 & 0 \\
\hline & 0.49 & 1.00 & 1.00 & 0.90 \\
\hline & 0.71 & 1.00 & 1.00 & 0.77 \\
\hline & 0.14 & 0.99 & 0.85 & 0.80 \\
\hline & 0.95 & 1.00 & 1.00 & 0.10 \\
\hline & 0.79 & 0.87 & 0.87 & 0 \\
\hline & 0.42 & 0.58 & 0.59 & 0 \\
\hline & 0.45 & 0.83 & 0.38 & 0.04 \\
\hline & 0.86 & 0.94 & 0.91 & 0.06 \\
\hline & 0.79 & 0.94 & 0.82 & 0.08 \\
\hline
\end{tabular}

$P$, particle perimeter; $A$, particle area; $P_{\mathrm{c}}$, perimeter of the convex hull; $A_{\mathrm{c}}$, area of the convex hull; width, shortest particle axis; length, longest particle axis.

remained undisturbed for 1 hour to allow sedimentation of particles $>2 \mu \mathrm{m}$. Finally, EC and $\mathrm{pH}$ were measured with a $\mathrm{pH}$ and conductivity meter, S47-K (Mettler Toledo, Greifensee, Switzerland). The cations comprising $\left(\mathrm{Na}^{+}, \mathrm{K}^{+}, \mathrm{Ca}^{2+}\right.$ and $\left.\mathrm{Mg}^{2+}\right)$ the colloid suspension were determined with ICP-OES optical emission spectroscopy (Arcos EOP, Spectro A.I. GmbH, Kleve, Germany).

Aggregate stability tests. Soil aggregate stability was evaluated using two main analyses, traditional wet sieving (Diaz-Zorita et al., 2002) and laser diffraction (Rawlins et al., 2013), to measure disaggregation dynamics. Both of these analyses require fast wetting (10 minutes with $450 \mathrm{ml}$ of deionized water) (Le Bissonnais, 1996) at an early stage, but soil samples were first grouped and treated in several ways so that slaking might be distinguished from physical-chemical dispersion during the analyses. Aggregate samples were grouped and treated as follows (Dal Ferro et al., 2012): (i) no pretreatment $(\mathrm{Fw})$, (ii) pretreatment in $5 \mathrm{ml}$ ethanol (Eth) to test aggregate dissolution and water dispersion by substituting air with a polar liquid before energy was applied and (iii) pretreatment in $5 \mathrm{ml}$ benzene (Benz) to coat the aggregates and emphasize the hydrophobic nature of SOC compounds.

Wet aggregate stability. Wet sieving was carried out with a Tiulin apparatus following the procedure described by Bocchi et al. (2008). Specifically, $10 \mathrm{~g}$ of pretreated soil aggregates were carefully sieved through a $200-\mu \mathrm{m}$ mesh and then vertically and mechanically oscillated (30 oscillations minute ${ }^{-1}$ ). Aggregates that adhered to the sieve were oven-dried at $105^{\circ} \mathrm{C}$ overnight and then weighed. To each dried sample $25 \mathrm{ml}$ of a solution $\left(40 \mathrm{~g}^{-1}\right.$ sodium hexametaphosphate and $10 \mathrm{gl}^{-1}$ sodium carbonate) was added and allowed to rest for 24 hours. Any sieve-retained material was washed with deionized water on a $200-\mu \mathrm{m}$ sieve and oven-dried again, and coarse sand content $(200-2000 \mu \mathrm{m})$ was determined. The wet aggregate stability index (WASI) was calculated as follows:

$$
\mathrm{WASI}=\frac{a_{\mathrm{as}}-\mathrm{cs}}{a_{\mathrm{bs}}-\mathrm{cs}} \times 100,
$$

where $a_{\mathrm{bs}}$ and $a_{\mathrm{as}}$ are the weights of the aggregates before and after sieving, respectively, and cs is the weight of the coarse sand fraction measured after dispersion. Wet sieving is indicated as WASI $_{\mathrm{Fw}}$ (fast

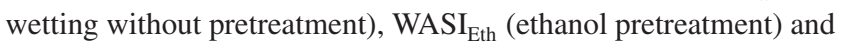
WASI $_{\text {Benz }}$ (benzene pretreatment).

Aggregate stability with laser diffraction. The kinetics of aggregate disintegration were determined with a Mastersizer 2000 laser diffraction granulometer (Malvern, Instruments Ltd, Malvern, UK). With this technique, we investigated the disaggregation behaviour 
(a)

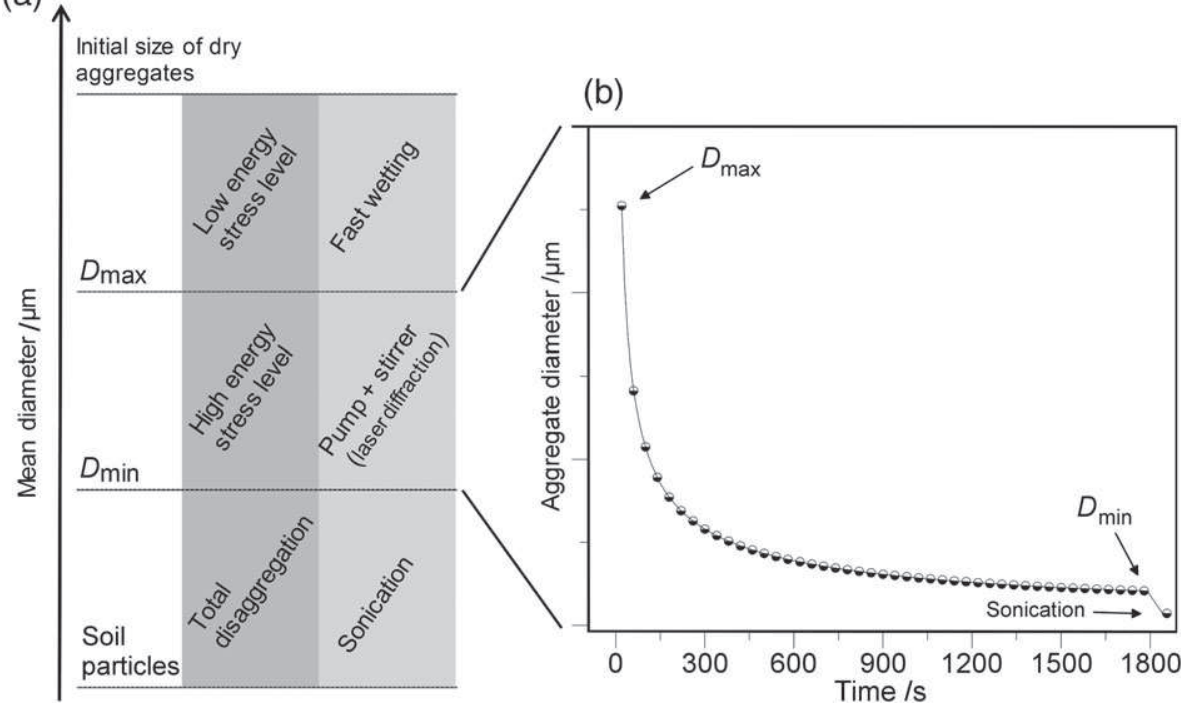

Figure 1 Graphical representation of (a) aggregate stability as a result of different energy stress levels and (b) disaggregation dynamics estimated with laser diffraction analysis.

of soil aggregates in response to different energy intensities (Rawlins et al., 2013). After pretreatment, the suspensions were transferred carefully to the instrument dispersion unit. The pump (1750 revolutions minute ${ }^{-1}$ ) and stirrer (700 revolutions minute ${ }^{-1}$ ) speeds were set to circulate all aggregates. A complete cycle of analysis was set to last $1800 \mathrm{~s}$ (30 minutes), with a time interval of $10 \mathrm{~s}$ between successive analyses (180 in total). After analysis, each sample underwent at least 1 minute of ultrasound, which led to complete aggregate disintegration (Bieganowski et al., 2010).

Aggregate disaggregation dynamics are described with the hyperbolic model:

$$
\begin{gathered}
D_{\mathrm{m}}(t)=D_{\max } \times\left(1-\frac{a t}{1+\frac{a t}{b}}\right), \text { with } t<t_{\mathrm{lim}}, \\
D_{\mathrm{m}}(t)=D_{\mathrm{min}}, \text { with } t \geq t_{\mathrm{lim}},
\end{gathered}
$$

where $D_{\mathrm{m}}(\mu \mathrm{m})$ represents the median aggregate diameter at time $t, D_{\max }$ is the median aggregate diameter at the beginning of the laser measurement $(t=0), a$ is the slope of the curve, which represents the speed of aggregate disruption, $b$ is the asymptote and $D_{\min }$ is the smallest aggregate diameter (Figure 1). Before interpolation, all observed data were standardized based on their elementary particle content by subtracting the median aggregate diameter of the sonicated material (Rawlins et al., 2013). According to the parameterization of disaggregation dynamics, $D_{\max }$ represents aggregate resistance to the fast wetting procedure; $D_{\max }$ corresponds to a low stress energy level because it is the first aggregate diameter measured after fast wetting. Indices $a, b$ and $D_{\min }$ describe aggregate susceptibility to disruption from high stress energy levels (applied by pump and stirrer in this case) during laser analyses. Larger values of $a$ and $b$ indicate faster disaggregation, whereas smaller values of $D_{\min }$ indicate weak resistance to high energy stress (Figure 1).

\section{Statistical analyses}

Soil properties for each soil type were analysed separately with a one-way analysis of variance (ANOVA) that considered carbon management (four treatments) as the fixed factor and the block (three blocks) as a random factor (Table 4). The assumptions of ANOVA of normality and homogeneity of the variances of the residuals were tested for all variables with the Shapiro-Wilk test $(P>0.05)$ and the Bartlett test $(P>0.05)$, respectively. Mean differences were deemed significant based on Fisher's least significant difference (LSD) at $P<0.05$. Aggregate stability curves were compared statistically, and differences in the combined water retention curves compared with individual ones were established with a partial $F$ test:

$$
F=\frac{\left(\mathrm{SSQ}_{\text {comb }}-\mathrm{SSQ}_{\mathrm{sep}}\right) /\left(\mathrm{df}_{\text {comb }}-\mathrm{df}_{\text {sep }}\right)}{\left(\mathrm{SSQ}_{\mathrm{sep}} / \mathrm{df}_{\mathrm{sep}}\right)},
$$

where SSQ is the sum of squares of the fitted against observed curves (comb, combined curves; sep, separate curves) and $\mathrm{df}$ represents the degrees of freedom (Schabenberger \& Pierce, 2002). Finally, after checking that variables were normally distributed, the Pearson correlation coefficient was calculated to estimate a possible linear relation between the aggregate stability indices and physical-chemical properties.

\begin{tabular}{|c|c|c|c|c|c|}
\hline Source & $\begin{array}{l}\text { Degrees of } \\
\text { freedom }\end{array}$ & $\begin{array}{l}\text { Sum of } \\
\text { squares }\end{array}$ & $\begin{array}{l}\text { Mean } \\
\text { squares }\end{array}$ & $F$ ratio & $P$ value \\
\hline Blocks & 2 & 0.004 & 0.002 & 0.849 & 0.474 \\
\hline $\begin{array}{c}\text { Main effects } \\
\text { (residual) }\end{array}$ & 3 & 0.342 & 0.114 & 44.50 & 0.002 \\
\hline Error & 6 & $1.92810^{-4}$ & $3.21410^{-5}$ & & \\
\hline Total & 11 & 0.362 & & & \\
\hline
\end{tabular}

Table 4 Analysis of variance for soil organic carbon treatment replicated three times in sandy loam soil in a randomized block design 
Table 5 Estimates of total pore volume, soil organic carbon (SOC) content and contact angle in clay and sandy loam aggregates under different carbon managements. Standard errors in brackets $(n=3)$. Results from the analysis of variance are given below the values of the variables

\begin{tabular}{|c|c|c|c|c|c|c|c|}
\hline Soil type & Treatment & $\begin{array}{l}\text { Total pore } \\
\text { volume } / \mathrm{cm}^{3}\end{array}$ & & $\begin{array}{l}\text { SOC content } \\
/ \mathrm{g} \mathrm{kg}^{-1}\end{array}$ & & $\begin{array}{l}\text { Contact } \\
\text { angle / }\end{array}$ & \\
\hline \multirow[t]{9}{*}{ Clay } & $\mathrm{NR}^{\mathrm{a}}$ & 0.110 & & 8.6 & & 49.87 & \\
\hline & $\mathrm{R}^{\mathrm{b}}$ & 0.097 & & 8.4 & & 52.95 & \\
\hline & $\mathrm{BC} 20^{\mathrm{c}}$ & 0.122 & & 11.3 & & 49.63 & \\
\hline & $\mathrm{BC} 40^{\mathrm{d}}$ & 0.117 & & 12.7 & & 56.09 & \\
\hline & & Mean square & $3.4210^{-4}$ & Mean square & 0.13 & Mean square & 27.71 \\
\hline & & SE & 0.01 & SE & 0.21 & SE & 3.04 \\
\hline & & $F$ ratio & 10.66 & $F$ ratio & 104.2 & $F$ ratio & 3.46 \\
\hline & & $P$ & $<0.01$ & $P$ & $<0.001$ & $P$ & Ns \\
\hline & & LSD & 0.011 & LSD & 0.071 & & \\
\hline \multirow[t]{8}{*}{ Sandy loam } & NR & 0.238 & & 5.9 & & 47.44 & \\
\hline & $\mathrm{R}$ & 0.232 & & 7.0 & & 47.90 & \\
\hline & $\mathrm{BC} 20$ & 0.258 & & 8.9 & & 51.70 & \\
\hline & & Mean square & $1.6110^{-3}$ & Mean square & 0.11 & Mean square & 13.04 \\
\hline & & SE & 0.02 & SE & 0.19 & SE & 2.08 \\
\hline & & $F$ ratio & 2.29 & $F$ ratio & 44.49 & $F$ ratio & 1.68 \\
\hline & & $P$ & NS & $P$ & $<0.001$ & $P$ & NS \\
\hline & & & & LSD & 0.101 & & \\
\hline
\end{tabular}

${ }^{a} \mathrm{NR}$, no crop residue incorporation or biochar addition.

${ }^{\mathrm{b}} \mathrm{R}$, crop residue incorporation.

${ }^{\mathrm{c}} \mathrm{BC} 20$, biochar addition $\left(20 \mathrm{Mg} \mathrm{ha}^{-1}\right)$.

${ }^{\mathrm{d}} \mathrm{BC} 40$, biochar addition (40 $\mathrm{Mg} \mathrm{ha}^{-1}$ ).

SE, standard error; NS, not significant; LSD, least significant difference.

\section{Results}

\section{Aggregate pore-size distribution and SOC content}

Total pore volume (TPV), estimated with mercury porosimetry in the range of $0.0074-100 \mu \mathrm{m}$ (Table 5), averaged $0.25 \mathrm{~cm}^{3} \mathrm{~g}^{-1}$ in sandy loam and about half this value in clay $\left(0.11 \mathrm{~cm}^{3} \mathrm{~g}^{-1}\right)$ aggregates. Carbon management significantly influenced the structure of the clay soil; the largest porosity was detected in $\mathrm{BC} 20$ treatment $\left(0.122 \mathrm{~cm}^{3} \mathrm{~g}^{-1}\right)$ and the smallest porosity with residue (R) incorporation $\left(0.097 \mathrm{~cm}^{3} \mathrm{~g}^{-1}\right)$. In sandy loam soil, there was no significant effect (Table 5). In clay soil, pore-size distribution differed between treatments in pores $<30 \mu \mathrm{m}$, in particular in ultramicropores $(0.1-5 \mu \mathrm{m})$ and micropores $(5-30 \mu \mathrm{m})$ (Figure $2 \mathrm{a})$. In contrast, this effect was magnified in sandy loam soil with cryptopores $(0.0074-0.1 \mu \mathrm{m})$ (Figure 2b). Pores larger than $30 \mu \mathrm{m}$ accounted for $17 \%$ and $10 \%$ of total aggregate porosity in clay and sandy loam soils, respectively. No statistical difference was observed in the residue or biochar treatments.

Soil organic carbon (SOC) content ranged from 8.6 to $12.7 \mathrm{~g} \mathrm{~kg}^{-1}$ in clay and from 5.9 to $10.03 \mathrm{~g} \mathrm{~kg}^{-1}$ in sandy loam aggregates (Table 5). Residue and biochar treatments enhanced SOC content in both soil aggregates compared, on average, with the control by $+6 \%(\mathrm{R}),+39 \%(\mathrm{BC} 20)$ and $+58 \%$ (BC40). Clay and sandy loam soils behaved differently with different carbon inputs (Table 5). In clay aggregates, only biochar inputs increased SOC content by $23.9 \%(\mathrm{BC} 20)$ and $32.3 \%(\mathrm{BC} 40)(P<0.05)$. In sandy loam soil, residues significantly enhanced SOC content (15.7\%), and biochar inputs raised it by $+33.7 \%$ in $\mathrm{BC} 20$ and $+42.7 \%$ in $\mathrm{BC} 40$ $(P<0.05)$, relative to the control (Table 5).

\section{Contact angle}

Soil-water contact angle (CA) was $49.4^{\circ}$ in sandy loam aggregates and $52.1^{\circ}$ in clay aggregates on average, revealing a general small degree of hydrophobicity in both soil types. Both biochar doses produced a slight increase (not significant) in the soil-water contact angle (from $47.9^{\circ}$ in $\mathrm{R}$ and $47.4^{\circ}$ in $\mathrm{NR}$, on average to $51.2^{\circ}$ in $\mathrm{BC}$ ) in sandy loam soil; only BC40 showed a tendency to increase hydrophobicity $\left(56.09^{\circ}\right)$ in clay soil (Table 5) compared with the control, $\mathrm{R}$ and $\mathrm{BC} 20$ (50.8 ${ }^{\circ}$ on average).

\section{Aggregate morphology characterization}

Microscope visually-determined aggregate size revealed that their equivalent circle diameter (ECD) ranged between 1000 and $1500 \mu \mathrm{m}$ and highlighted some initial uniformity between soil types and treatments. The ECD of clay aggregates varied between $1168.2 \mu \mathrm{m}$ (BC20) and $1245.1 \mu \mathrm{m}$ (BC40), with slight variation related to treatment. The results were similar for sandy loam aggregates that ranged in ECD between $1282.7 \mu \mathrm{m}(\mathrm{R})$ and 1412.7 (NR) (Table 6). Morphologic characterization showed asymmetrical shapes with irregular surfaces characterized by low 


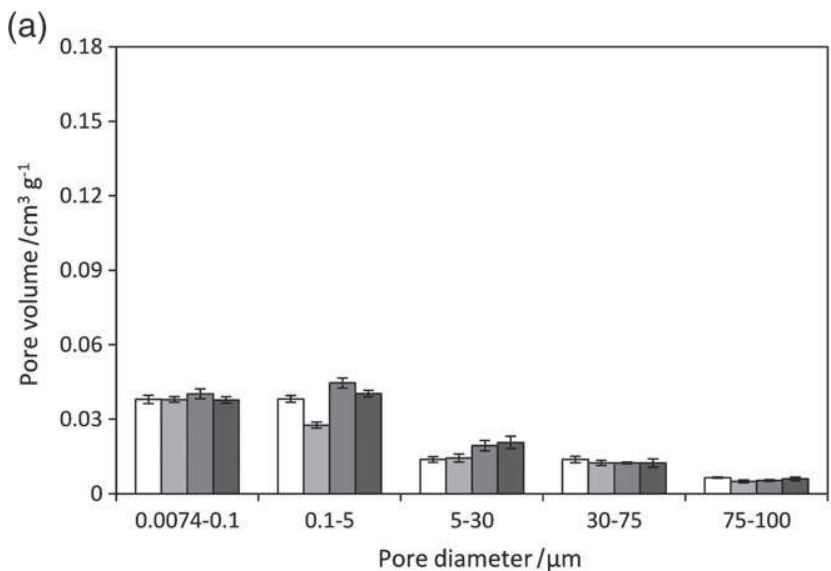

(b)

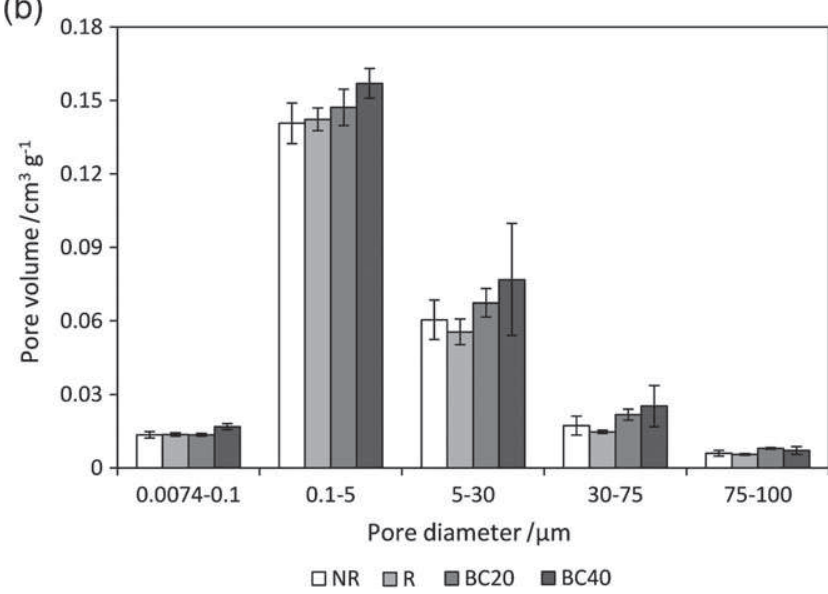

Figure 2 Pore-size distributions of (a) clay and (b) sandy loam aggregates under different carbon managements. Error bars represent standard error $(n=3)$.

circularity ( 0.6 , on average). In particular, clay aggregates were more rounded (i.e. greater circularity and less elongation) and smoother (greater convexity) than sandy loam ones, although each had a similar solidity $(\mathrm{S}=0.92$, on average). A biochar-induced tendency towards increased solidity and elongation indices (from 0.91 to 0.92 and from 0.21 to 0.23 , respectively) was noted only in clay, whereas sandy loam aggregates showed no sensitivity to changes in shape from either residues or biochar inputs.

\section{Scanning electron microscope images}

Non-biochar-treated clay aggregate particles (Figure 3a) were characterized by scabrous surfaces and irregular shapes. By contrast, sandy loam aggregates had prismatic particles intercalated with thinner and lamellar ones (Figure 3c). Powdery biochar was clearly visible on the surface of aggregate particles in both soils (Figure 3b,d), which suggests that the organic and inorganic materials interacted physically to promote aggregation. This was also confirmed by visual inspection of aggregate images (Figure 4). Biochar did not simply cover the surface of the aggregates, but interacted with both internal and external particles. The red arrows in Figure 4 indicate that biochar was enclosed in soil particles and was easily visible to the naked eye.

\section{Electrochemical properties of dispersed colloids}

A general increase in electrical conductivity (EC) was observed in the dispersed colloid solution of biochar-treated aggregates with respect to NR and R in both soils (Table 7). Amendment with BC20 and $\mathrm{BC} 40$ significantly affected mono- $\left(\mathrm{K}^{+}\right)$and bivalent cations $\left(\mathrm{Ca}^{2+}\right.$ and $\left.\mathrm{Mg}^{2+}\right)$, whereas both benzene and ethanol pretreatments increased the concentration of dispersible cations. In particular, ethanol increased $\mathrm{Ca}^{2+}$ and $\mathrm{Mg}^{2+}$ concentrations, whereas benzene released monovalent cations. By releasing cations and changing physical-chemical properties of soil aggregates, biochar influenced $\mathrm{K}^{+}, \mathrm{Ca}^{2+}$ and $\mathrm{Mg}^{2+}$ cations relative to $\mathrm{NR}$ and $\mathrm{R}$, as shown in Table 7.

\section{Wet aggregate stability}

Measurements of wet aggregate stability (WASI) varied with soil and pretreatment type. Average values for non-pretreated samples $\left(\mathrm{WASI}_{\mathrm{Fw}}\right.$ ) were $80.1 \%$ in clay and $10.0 \%$ in sandy loam soil (Table 8). Ethanol and benzene affected aggregate stability in all treatments. Results varied widely. In the $\mathrm{WASI}_{\text {Eth }}$ experiment, values averaged $89.0 \%$ in clay and $49.0 \%$ in sandy loam, whereas in the $\mathrm{WASI}_{\text {Benz }}$ experiment values increased breakdown (61.4\%) in clay and stabilization mechanisms $(49.4 \%)$ in sandy loam compared with WASI $_{\mathrm{Fw}}$ values. All carbon inputs significantly improved $(P<0.05)$ sandy loam aggregate stability, which was especially highlighted in $\mathrm{WASI}_{\mathrm{Eth}}$ and $\mathrm{WASI}_{\mathrm{Fw}}$ (Table 8). By contrast, in clay, carbon inputs produced an effect only with ethanol pretreatment $\left(\mathrm{WASI}_{\mathrm{Eth}}\right)$, regardless of carbon type and amount applied.

Various relations between pretreatments and aggregate physical-chemical and structural properties were evident in the disaggregation dynamics of both soils (Figure 5). Wet aggregate stability with fast wetting ( $\mathrm{WASI}_{\mathrm{Fw}}$ ) was strongly correlated $(r=0.61, P<0.05)$ with CA in both soils, and with SOC and ultramicropores $(0.1-5 \mu \mathrm{m})$ in sandy loam. In both clay and

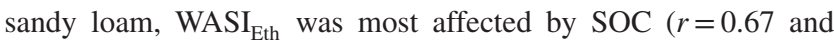
0.78 , respectively) and electrical conductivity $(r=0.59$ and 0.83 , respectively). By contrast, pore-size class was a strong predictor of $\mathrm{WASI}_{\mathrm{Benz}}$ for both clay (cryptopores $0.1-0.0074 \mu \mathrm{m}, r=0.76$, $P<0.05$ ) and sandy loam aggregates (macropores $10-75 \mu \mathrm{m}$, $r=-0.68, P<0.05)$. Mono- $\left(\mathrm{Na}^{+}, \mathrm{K}^{+}\right)$and bivalent $\left(\mathrm{Ca}^{2+}\right)$ cations affected clay WASI $_{\text {Benz }}$ negatively and sandy loam WASI $\mathrm{Eth}_{\text {th }}$ positively. Aggregate morphology was generally not correlated with aggregate stability. The solidity index was the only significant predictor of $\mathrm{WASI}_{\mathrm{Eth}}$ (Figure 5).

\section{Aggregate stability with laser diffraction}

Clay and sandy loam soils showed kinetic differences in disaggregation $(P<0.05)$ that were unrelated to pretreatment (Figure 6). Modelled disaggregation curves were characterized by larger $D_{\max }$ 
Table 6 Morphologic parameters of clay and sandy loam soil aggregates. Standard errors in brackets $(n=3)$

\begin{tabular}{|c|c|c|c|c|c|c|c|c|c|c|c|}
\hline \multirow{2}{*}{$\frac{\text { Soil }}{\text { Clay }}$} & \multirow{2}{*}{$\begin{array}{l}\text { Treatment } \\
\mathrm{NR}\end{array}$} & \multicolumn{2}{|l|}{$\mathrm{ECD}^{\mathrm{a}}$} & \multicolumn{2}{|c|}{ Circularity } & \multicolumn{2}{|c|}{ Convexity } & \multicolumn{2}{|c|}{ Sphericity } & \multicolumn{2}{|c|}{ Elongation index } \\
\hline & & 1197.4 & $(27.6)$ & 0.627 & $(0.017)$ & 0.868 & $(0.010)$ & 0.911 & $(0.005)$ & 0.210 & $(0.003)$ \\
\hline & $\mathrm{R}$ & 1176.1 & (41.4) & 0.636 & $(0.010)$ & 0.876 & $(0.007)$ & 0.911 & $(0.002)$ & 0.209 & $(0.007)$ \\
\hline & $\mathrm{BC} 20$ & 1168.2 & $(37.0)$ & 0.661 & $(0.017)$ & 0.893 & $(0.014)$ & 0.917 & $(0.004)$ & 0.226 & $(0.010)$ \\
\hline & $\mathrm{BC} 40$ & 1245.1 & $(15.5)$ & 0.634 & $(0.012)$ & 0.875 & $(0.007)$ & 0.921 & $(0.002)$ & 0.230 & $(0.001)$ \\
\hline \multirow[t]{4}{*}{ Sandy loam } & NR & 1412.7 & $(83.1)$ & 0.610 & $(0.017)$ & 0.850 & $(0.010)$ & 0.926 & $(0.001)$ & 0.223 & $(0.015)$ \\
\hline & $\mathrm{R}$ & 1282.7 & $(74.8)$ & 0.552 & $(0.030)$ & 0.808 & $(0.024)$ & 0.918 & $(0.003)$ & 0.231 & $(0.008)$ \\
\hline & $\mathrm{BC} 20$ & 1360.3 & $(122.7)$ & 0.603 & $(0.017)$ & 0.845 & $(0.010)$ & 0.922 & $(0.001)$ & 0.224 & $(0.001)$ \\
\hline & $\mathrm{BC} 40$ & 1297.7 & $(74.4)$ & 0.577 & $(0.024)$ & 0.831 & $(0.017)$ & 0.920 & $(0.002)$ & 0.239 & $(0.001)$ \\
\hline
\end{tabular}

${ }^{\mathrm{a} E C D}$, Equivalent circle diameter $/ \mu \mathrm{m}$.
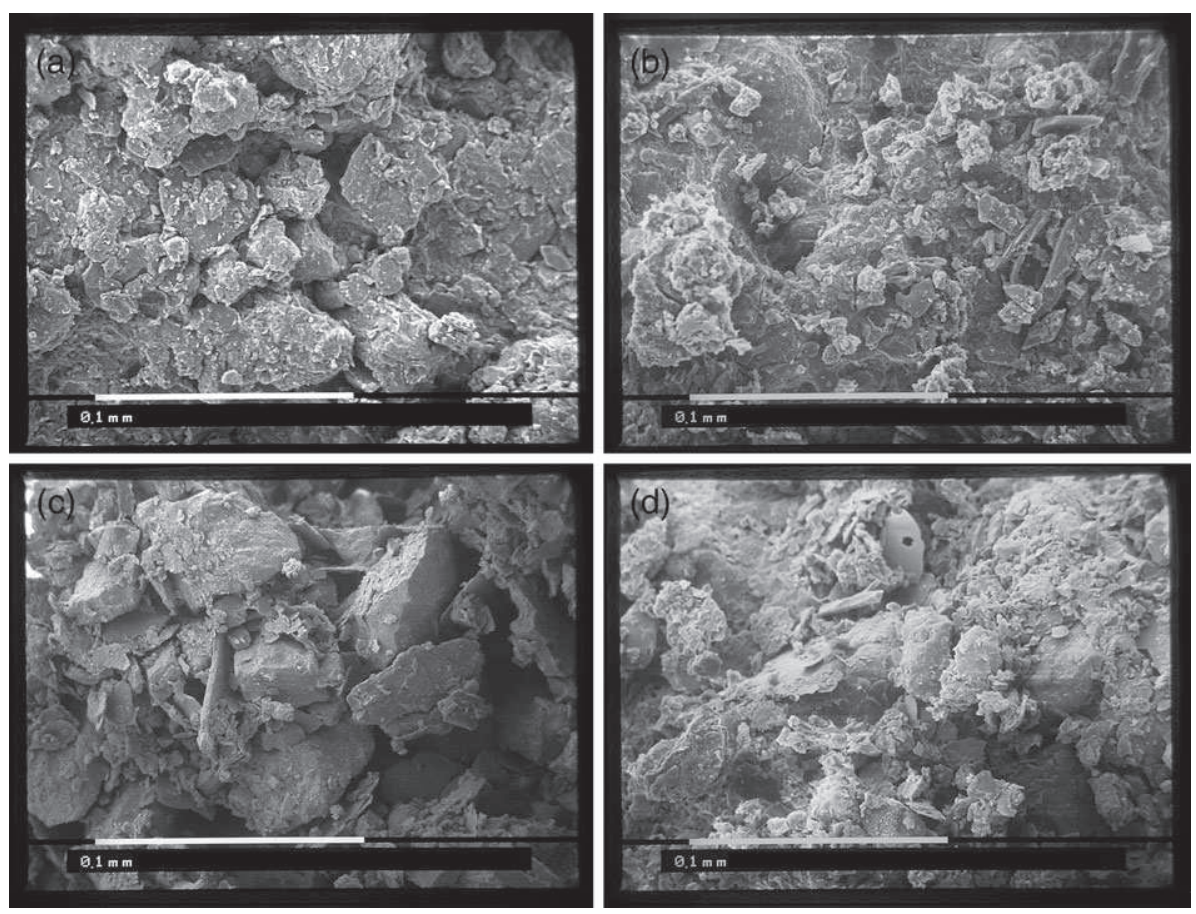

Figure 3 Scanning electron microscope images of clay soil (a) without biochar and (b) with biochar, and sandy loam soil (c) without biochar and (d) with biochar.

in clay than in sandy loam soils $(582.8 \mu \mathrm{m}$ versus $77.5 \mu \mathrm{m}$, on average) (Table 9), which suggests greater resistance to the fast-wetting procedure in clay-dominated aggregates. Strong disaggregation was observed in the clay soil until aggregates attained a size of about $30-50 \mu \mathrm{m}$ (about $600 \mathrm{~s}$ or 10 minutes of analysis). At this point, steady conditions continued until $D_{\min }$ values averaged $15.3 \mu \mathrm{m}$. On the other hand, sandy loam soils were affected by continuous disaggregation throughout the full $1800 \mathrm{~s}$ of analysis as they steadily reduced their aggregate diameter until $D_{\min }$ was $3.0 \mu \mathrm{m}$.

Other pretreatments showed similar dynamics between clay and sandy loam aggregates. Ethanol shifted the curves toward larger diameters (Figure 6c,d) compared to those without pretreatment, whereas benzene produced the opposite effect (Figure 6e,f). A general shift towards larger aggregate diameters was also observed in C-input soils, although the dynamics differed between clay and sandy loam soils. In the latter, aggregate stability was always favoured by biochar inputs and generally in accord with amount
(BC40 > BC20). In contrast, aggregate stability in clay was not affected by the larger amount of biochar.

Different disaggregation dynamics between clay and sandy loam soils were highlighted by the correlations in Figure 5. Clay cryptopores $(0.1-0.0074 \mu \mathrm{m})$ were associated with strong stability at high stress energy levels $\left(D_{\max }\right)$ for both Fw and Benz, whereas the slope of the curves (parameters $a$ and $b$ ) was most strongly correlated with macropore fractions (range, 100-30 $\mu \mathrm{m}$ ). In sandy loam, aggregate stability dynamics were dominated by carbon-related indices, which showed positive correlations with SOC and CA. Solidity was confirmed to be the only morphologic property that was correlated with the stability indices (e.g. $D_{\max }$ and $D_{\min }$ ).

\section{Discussion}

Our results have shown that biochar enhanced total pore volume by increasing the number of pores $<30 \mu \mathrm{m}$ in size, corroborating work by Ajayi et al. (2016) that used biochar powder in fine-textured 


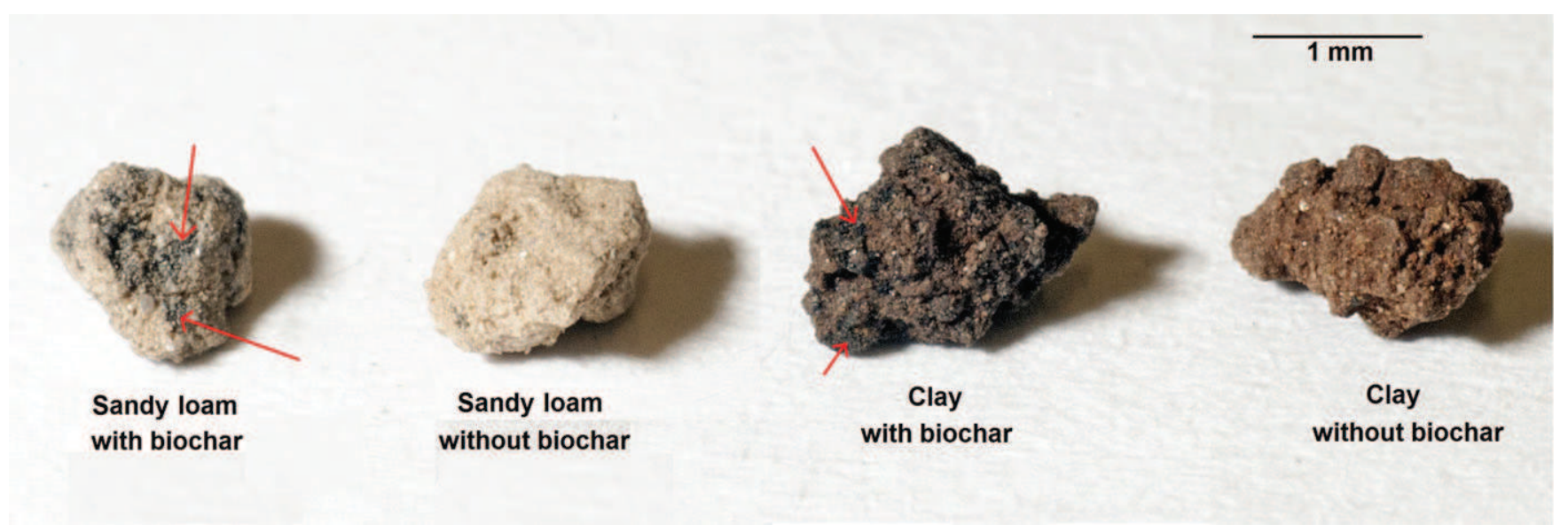

Figure 4 Visual displays of clay and sandy loam aggregates with the addition of biochar compared with aggregates without added biochar.

Table 7 Electrochemical properties ( $\mathrm{pH}, \mathrm{EC}, \mathrm{Na}^{+}, \mathrm{K}^{+}, \mathrm{Ca}^{2+}, \mathrm{Mg}^{2+}$ ) of colloidal suspensions without (Fw) and with (Eth, Benz) pretreatments. Standard error in brackets $(n=3)$

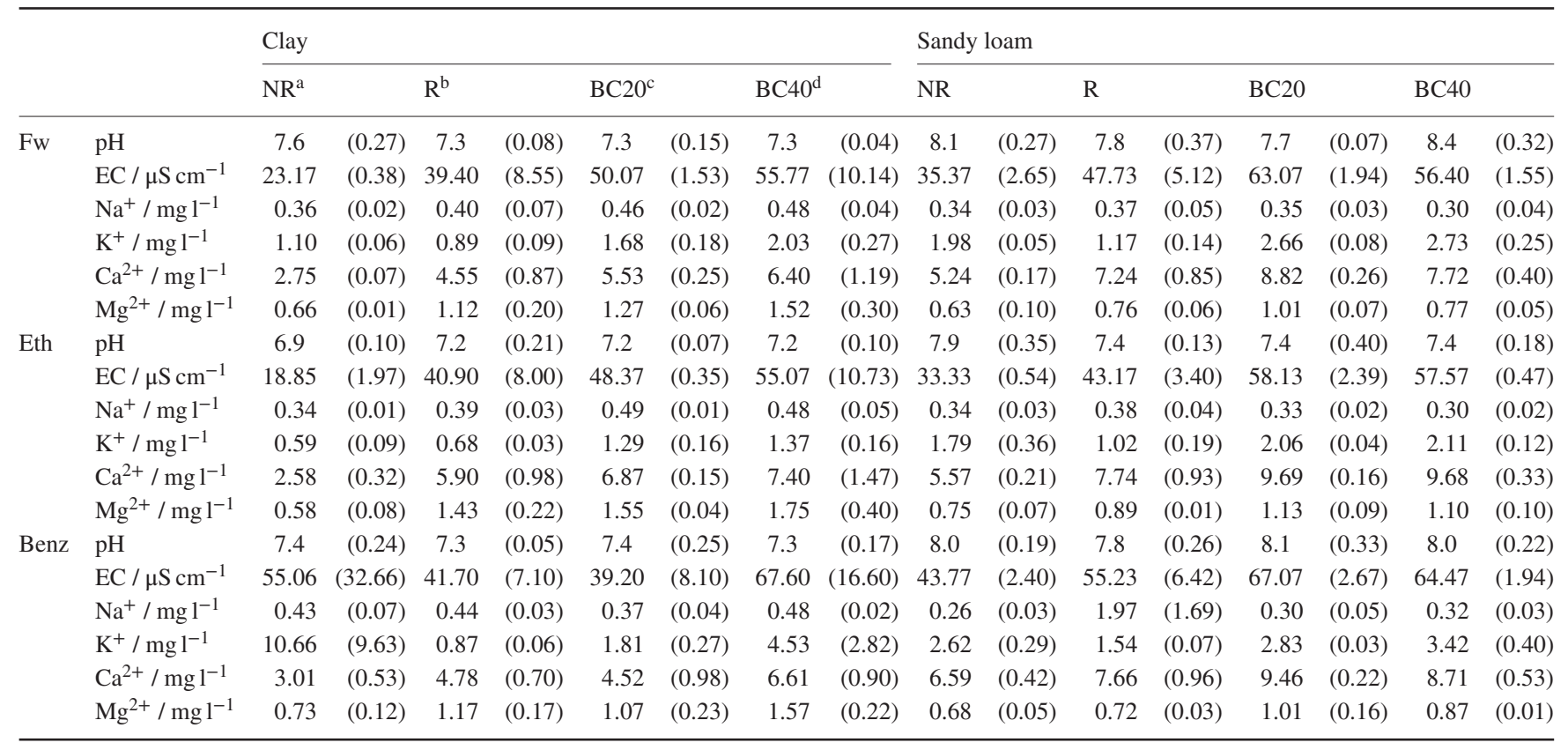

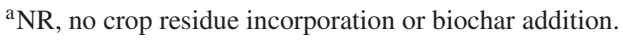

${ }^{\mathrm{b}} \mathrm{R}$, crop residue incorporation.

${ }^{\mathrm{c}} \mathrm{BC} 20$, biochar addition $\left(20 \mathrm{Mg} \mathrm{ha}^{-1}\right)$.

${ }^{\mathrm{d}} \mathrm{BC} 40$, biochar addition $\left(40 \mathrm{Mg} \mathrm{ha}^{-1}\right)$.

soils. Others (e.g. Andrenelli et al., 2016) have reported results that contrast with ours; they observed that biochar increased mesopores and macropores (i.e. $>30 \mu \mathrm{m}$ ). These authors found that biochar increased soil macroporosity between $5 \%$ and $20 \%$, and therefore TPV, by generating porosity between biochar and the surrounding soil particles. However, this effect occurred in silty loam and silty clay loam soils with biochar inputs (produced at high temperatures) of $10-14 \mathrm{Mg} \mathrm{ha}^{-1}$.

In our study, biochar was composed of two fractions (coarse particles and powder), but it is likely that only the powder had an effect during aggregation because the size of the coarse fraction was comparable to, or even larger than, the soil aggregates studied (1-2 mm). Crop residue incorporation did not affect pore-size distribution, even after 43 years of experimentation in the same soils, according to Pituello et al. (2016b). Nevertheless, residues did increase SOC content slightly, especially in the sandy loam soil, which accords with the findings of Powlson et al. (2011), who reported that SOC increased by $c$. $10 \%$ without residue incorporation. A much more substantial effect arose from an increase in SOC content with biochar, which was probably a result 
Table 8 Wet aggregate stability indices (WASI) of clay and sandy loam aggregate samples. Standard errors in brackets $(n=3)$

\begin{tabular}{|c|c|c|c|c|c|c|c|}
\hline Soil & Treatment & $\mathrm{WASI}_{\mathrm{FW}}$ & & WASI $_{\text {Eth }}$ & & WASI $_{\text {Benz }}$ & \\
\hline \multirow[t]{9}{*}{ Clay } & $\mathrm{NR}^{\mathrm{a}}$ & 76.0 & & 86.0 & & 56.1 & \\
\hline & $\mathrm{R}^{\mathrm{b}}$ & 85.9 & & 90.9 & & 72.0 & \\
\hline & $\mathrm{BC} 20^{\mathrm{c}}$ & 80.8 & & 89.7 & & 63.3 & \\
\hline & $\mathrm{BC} 40^{\mathrm{d}}$ & 78.0 & & 89.3 & & 54.3 & \\
\hline & & Mean square & 30.00 & Mean square & 17.82 & Mean square & 195.1 \\
\hline & & $\mathrm{SE}$ & 3.16 & SE & 2.44 & SE & 8.06 \\
\hline & & $F$ ratio & 3.41 & $F$ ratio & 5.97 & $F$ ratio & 1.11 \\
\hline & & $P$ & NS & $P$ & $<0.05$ & $P$ & NS \\
\hline & & & & LSD & 2.989 & & \\
\hline \multirow[t]{8}{*}{ Sandy loam } & NR & 6.6 & & 41.0 & & 49.9 & \\
\hline & $\mathrm{R}$ & 8.1 & & 47.2 & & 50.0 & \\
\hline & $\mathrm{BC} 20$ & 10.2 & & 54.7 & & 48.5 & \\
\hline & $\mathrm{BC} 40$ & 14.9 & & 53.2 & & 49.1 & \\
\hline & & $\mathrm{SE}$ & 3.53 & SE & 6.26 & SE & 0.73 \\
\hline & & $F$ ratio & 5.20 & $F$ ratio & 6.78 & $F$ ratio & 0.87 \\
\hline & & $P$ & $<0.05$ & $P$ & $<0.05$ & $P$ & NS \\
\hline & & LSD & 5.362 & LSD & 8.327 & & \\
\hline
\end{tabular}

${ }^{a} \mathrm{NR}$, no crop residue incorporation or biochar addition;

${ }^{\mathrm{b}} \mathrm{R}$, crop residue incorporation.

${ }^{\mathrm{c}} \mathrm{BC} 20$, biochar addition $\left(20 \mathrm{Mg} \mathrm{ha}^{-1}\right)$.

${ }^{\mathrm{d}} \mathrm{BC} 40$, biochar addition (40 $\left.\mathrm{Mg} \mathrm{ha}^{-1}\right)$.

SE, standard error; NS, not significant; LSD, least significant difference.

of two factors: (i) $\mathrm{C}$ input in the 2-year period was significantly larger with biochar than residues $(P<0.05)$ and estimated to be in the range of $30-70 \%$, depending on treatment, and (ii) biochar is very recalcitrant and degrades slowly in soil (Wang et al., 2016).

The shape of soil aggregates is important to soil physical processes, and this is particularly true for the packing density breakdown mechanism (Wang et al., 2014) and for shoot and root growth (Lipiec et al., 2016). At present, the scientific literature available on aggregate shape characteristics is limited. Early studies by Dexter (1985) reported that soil aggregate susceptibility to breakdown might be a result of bending stresses applied to their longest axis. The clay aggregates we analysed were rounder than the sandy loam ones ( $>\mathrm{C}$, circularity; $<\mathrm{E}_{\mathrm{i}}$, elongation), and they did show more stability to water stresses. However, this was probably a minor factor that affected wet aggregate stability. Indeed, breakdown mechanisms were mostly associated with the intrinsic texture and inner physical-chemical characteristics, which were also highlighted by the WASI results and disaggregation dynamics.

The physical protection inside aggregates is considered one of the main mechanisms leading to the long-lasting stability of biochar in soil (Burrell et al., 2016). Biochar might stabilize aggregates by interacting with soil particles resulting from large CEC (Glaser et al., 2002) and increasing hydrophobic components (Wang et al., 2017). Other authors have suggested that biochar might also compromise soil aggregate stability through chemical perturbation (e.g. release of monovalent cations, large increases in $\mathrm{pH}$, or negative clay particle surface charges) of colloid kinetics (Kumari et al., 2017). We observed similar results in clay aggregates: the largest biochar amount $\left(40 \mathrm{Mg} \mathrm{ha}^{-1}\right)$ induced some disaggregation dynamics that did not occur with intermediate carbon inputs (BC20, $\mathrm{R})$. In particular, this was observed after benzene pretreatment, a sensitive indicator of SOC content, and suggested that large applications of biochar might reverse aggregation processes in clay soils. An excess of negative charges and the mobilization of monovalent cations $\left(\mathrm{Na}^{+}, \mathrm{K}^{+}\right)$might also favour dispersion rather than stability of aggregates (Kumari et al., 2017). The negative correlations between $\mathrm{WASI}_{\text {Benz }}$ and both ionic strength (i.e. EC) and monovalent cations support this hypothesis.

The effect of biochar on colloid surface potentials was also verified (data not shown) by measuring the zeta potential $(\zeta \mathrm{n})$, which decreased from $-10.80 \mathrm{mV}$ in $\mathrm{NR}$ to $-13.18 \mathrm{mV}$ in BC40. These results suggest that the adsorption of organic components on to the surface of the colloid increased its negative surface charge and led to less stable aggregates (Seta \& Karathanasis, 1997). According to other authors (e.g. Xu, 2002), only a $\zeta$ n less than about $-30 \mathrm{mV}$ leads to a stable colloidal suspension and consequent disaggregation. In contrast, in sandy loam soil naturally poor in clay and less affected by the colloid repulsion phenomenon (Burrell et al., 2016), the addition of biochar promoted SOC-controlled aggregation. These results were emphasized by $\mathrm{WASI}_{\text {Eth }}$, which tests the wet mechanical cohesion by substituting air with a polar liquid before energy is applied. Immersion of ethanol-pretreated aggregates in water minimized the slaking of dried soil aggregates and emphasized their resistance to dissolution and the dispersive action of water. The greater stability observed in biochar-amended soils and positive correlation between $\mathrm{WASI}_{\mathrm{Eth}}$ and SOC suggests 
론 \begin{tabular}{lllllll|l|l|l|l|l|l|l|l|l|l|l|l|l}
0.14 & 0.15 & 0.18 & 0.04 & -0.66 & $\mathbf{0 . 8 0}$ & -0.83 & -0.30 & 0.47 & -0.36 & 0.18 & 0.07 & $\mathbf{0 . 6 2}$ & 0.04 & 0.02 & 0.25 & 0.27 & 0.16 & 0.25 & 0.23
\end{tabular} $\begin{array}{lllllllllllllllllllll}\mathbf{0 . 6 0} & \mathbf{0 . 7 6} & 0.00 & -0.13 & -0.01 & -0.19 & 0.13 & 0.22 & -0.01 & 0.02 & 0.35 & 0.26 & 0.43 & -0.03 & \mathbf{0 . 6 8} & -0.24 & -0.03 & 0.04 & -0.24 & -0.25\end{array}$ \begin{tabular}{ll|l|l|l|l|l|l|l|l|l|l|l|l|l|l|l|l|l|l|}
-0.74 & -0.91 & 0.07 & 0.32 & 0.09 & 0.26 & -0.25 & -0.15 & 0.25 & -0.02 & -0.29 & -0.19 & -0.29 & 0.11 & -0.49 & 0.52 & 0.36 & 0.07 & 0.50 & 0.50 \\
\hline
\end{tabular}

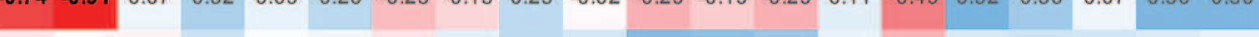

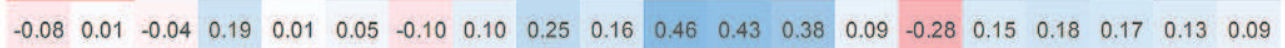
$\begin{array}{lllllllllllllllllllllll}-0.28 & -0.68 & -0.01 & 0.22 & 0.09 & 0.06 & 0.14 & -0.49 & 0.25 & 0.11 & -0.38 & -0.32 & -0.01 & 0.30 & 0.13 & 0.34 & 0.18 & 0.35 & 0.37 & 0.38\end{array}$ $\begin{array}{llllllllllllllllllllll}0.23 & 0.36 & -0.53 & -0.40 & -0.70 & 0.28 & -0.21 & -0.29 & -0.35 & -0.42 & 0.01 & -0.12 & 0.14 & -0.49 & -0.77 & -0.49 & -0.49 & -0.70 & -0.49 & -0.47\end{array}$ $\begin{array}{lllllllllllllllllllll}-0.38 & 0.00 & 0.60 & -0.05 & \mathbf{0 . 5 9} & -0.11 & -0.12 & 0.55 & -0.06 & 0.33 & 0.09 & 0.12 & -0.20 & 0.02 & 0.47 & 0.21 & 0.45 & 0.26 & 0.19 & 0.22\end{array}$ $\begin{array}{llllllllllllllllllll}-0.48 & -0.30 & 0.33 & -0.02 & 0.75 & -0.57 & 0.47 & 0.48 & -0.36 & 0.36 & -0.13 & -0.03 & -0.60 & -0.17 & 0.15 & -0.52 & -0.48 & -0.42 & -0.35 & -0.33\end{array}$ \begin{tabular}{lllllllllll|l|l|l|l|l|l|l|l|l}
-0.35 & -0.10 & 0.36 & -0.07 & 0.45 & -0.04 & 0.03 & 0.03 & 0.11 & 0.07 & 0.30 & 0.36 & 0.05 & 0.37 & -0.20 & 0.01 & -0.10 & -0.10 & 0.17 & 0.19
\end{tabular} \begin{tabular}{llllllllll|l|l|l|l|l|l|l|l|l|l|l}
0.51 & 0.48 & -0.22 & 0.12 & -0.48 & 0.36 & -0.37 & -0.14 & 0.08 & -0.48 & 0.11 & -0.04 & 0.42 & -0.22 & 0.14 & 0.15 & 0.09 & 0.33 & -0.23 & -0.25
\end{tabular} $\begin{array}{lllllllllllllllllllll}0.15 & 0.30 & -0.14 & -0.48 & 0.21 & -0.32 & 0.37 & 0.02 & -0.25 & 0.18 & 0.21 & 0.24 & 0.00 & 0.09 & 0.02 & -0.14 & -0.02 & -0.13 & -0.03 & -0.02\end{array}$

SANDY-LOAM \% \begin{tabular}{l|lll|l|l|lll|l|l|l|l|l|l|l|l|l|l|l|l} 
WASI $_{\text {FW }}$ & 0.24 & 0.28 & 0.25 & $\mathbf{0 . 6 1}$ & 0.47 & 0.04 & -0.02 & -0.22 & $\mathbf{0 . 7 7}$ & $\mathbf{0 . 5 7}$ & 0.07 & 0.13 & -0.32 & 0.36 & 0.13 & 0.46 & -0.31 & 0.53 & 0.36 & 0.17
\end{tabular} \begin{tabular}{llllllllllllllllll|l|l|l|l} 
WASl $_{\text {Eth }}$ & 0.20 & 0.01 & -0.11 & 0.52 & 0.33 & 0.27 & -0.25 & -0.37 & 0.78 & 0.40 & 0.13 & 0.17 & -0.20 & 0.20 & -0.19 & 0.83 & -0.09 & 0.33 & 0.79 & 0.57
\end{tabular} \begin{tabular}{l|lll|l|l|llllllllllllllllllll} 
WASI $_{\text {Benz }}$ & -0.68 & -0.54 & -0.55 & 0.02 & 0.10 & -0.18 & 0.16 & 0.35 & -0.37 & -0.48 & 0.18 & 0.16 & 0.33 & -0.31 & -0.10 & -0.38 & -0.02 & 0.26 & -0.29 & -0.15
\end{tabular}

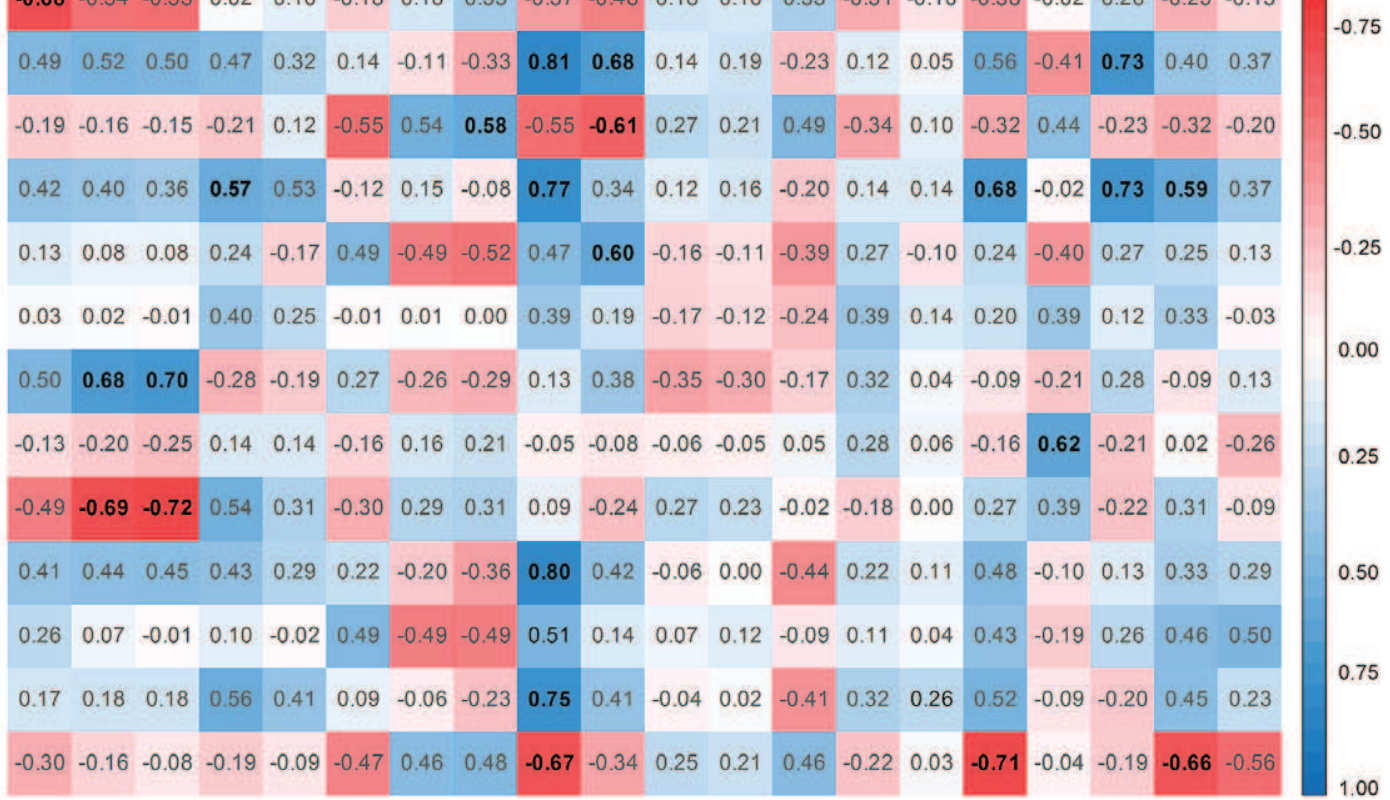

Figure 5 Correlation coefficient matrix of selected aggregate properties in clay and sandy loam soils. Bold font values are significant at $P<0.05$. CA, contact angle; $C$, Circularity; $C_{\mathrm{x}}$, convexity, $S$, sphericity; $E_{\mathrm{i}}$, elongation index. 
(a)

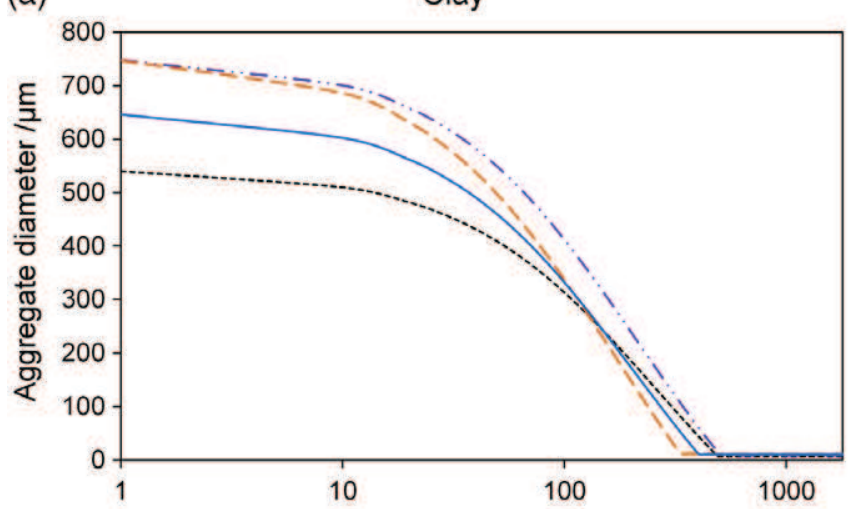

(c)

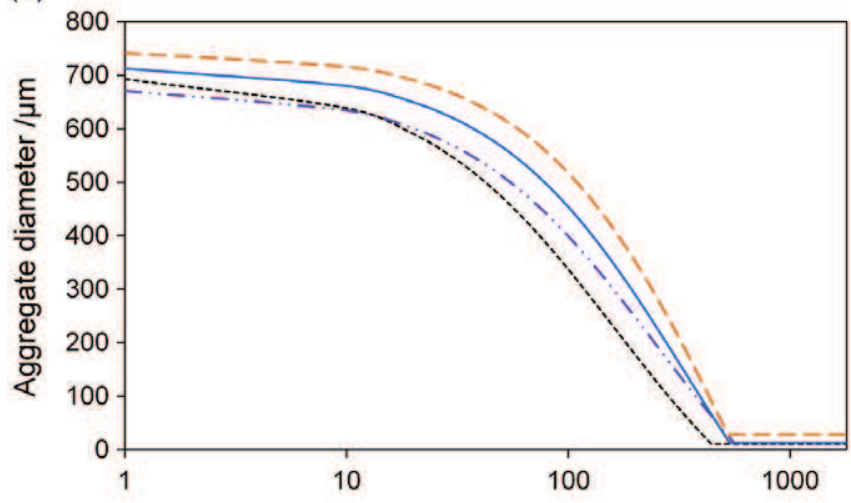

(e)

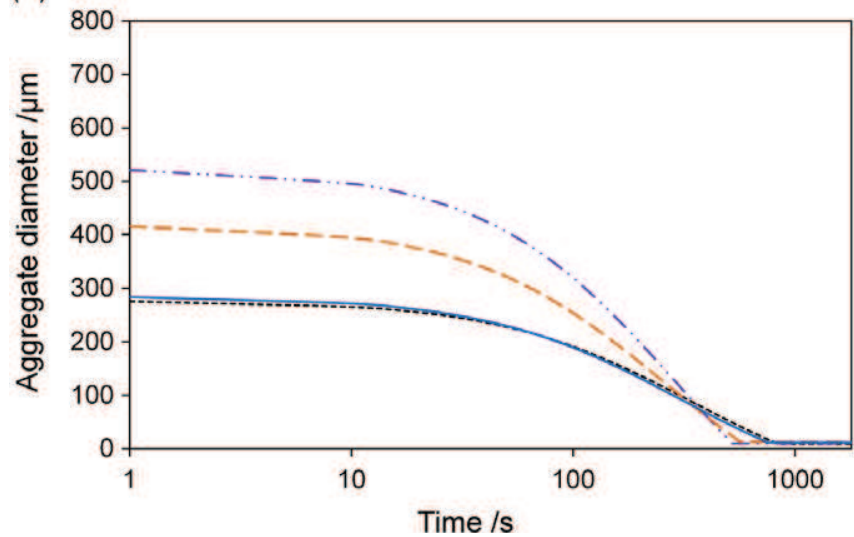

(b)

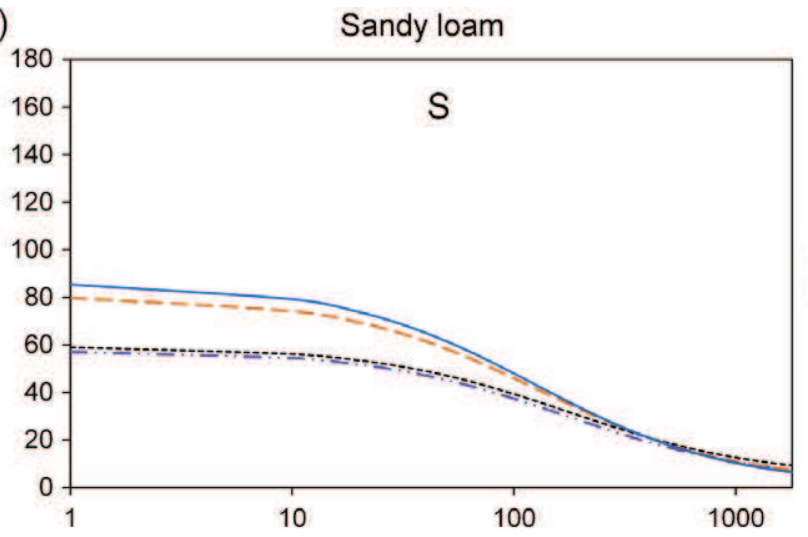

(d)

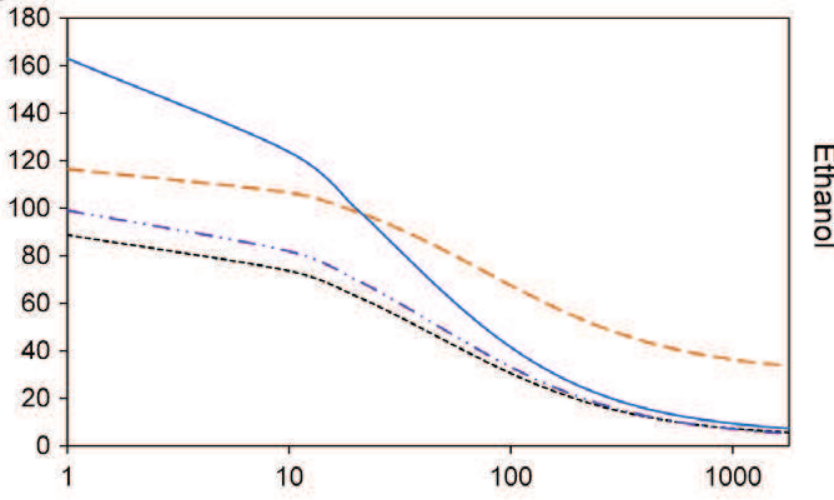

(f)

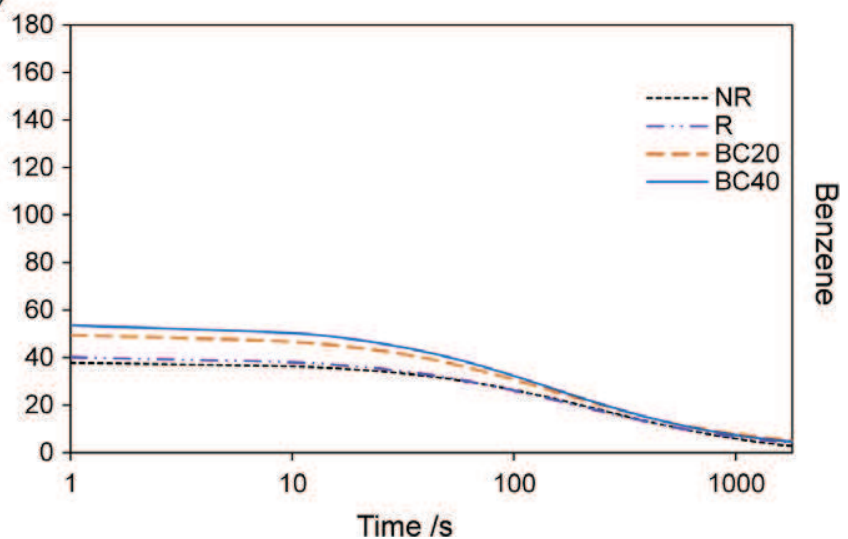

Figure 6 Curve showing disaggregation dynamics estimated by laser diffraction analysis in clay (a, c, e) and sandy loam (b, d, f) soils after the following pretreatments: Fw (a, b), Eth (c, d, ) and Benz (e, f).

that chemical bonds are favoured by organic carbon inputs. Note that aggregate stability after fast wetting and benzene pretreatments was also slightly affected by changes in soil structure that was estimated by pore-size distribution. Furthermore, it was positively correlated (Figure 5) with small-size pores $(0.1-0.0074 \mu \mathrm{m}$, in clay; $5-0.1 \mu \mathrm{m}$, in sandy loam) and negatively correlated with macropores (100-75 $\mu \mathrm{m}$, in sandy loam). The ability of internal pore space to modify aggregate stability by changing the internal air pressure during aggregate wetting has been discussed by other researchers (e.g. Zaher et al., 2005). Larger volumes of small pores might reduce rapid entry of water that would increase internal air pressure and cause aggregate disruption.

The dynamics of aggregate breakdown measured with laser diffraction were characterized by a two-stage behaviour, with faster disruption at the initial stage of the experiment followed by slower disruption at the end, according to Fajardo et al. (2016). This same dynamic was particularly pronounced in our study for the clay aggregates, which disrupted very quickly in the first $600 \mathrm{~s}$ of the 
Table 9 Fitting parameters of disaggregation curve after laser diffraction analysis in clay and sandy loam soils without (Fw) and with (Eth, Benz) pretreatments. Standard error in brackets

\begin{tabular}{|c|c|c|c|c|c|c|c|c|c|c|c|c|c|c|c|c|c|}
\hline \multirow[b]{3}{*}{$\mathrm{Fw}$} & \multirow[b]{3}{*}{$D_{\max } / \mu \mathrm{m}$} & \multicolumn{8}{|l|}{ Clay } & \multicolumn{8}{|c|}{ Sandy loam } \\
\hline & & \multicolumn{2}{|l|}{$\mathrm{NR}^{\mathrm{a}}$} & \multicolumn{2}{|l|}{$\mathrm{R}^{\mathrm{b}}$} & \multicolumn{2}{|l|}{$\mathrm{BC} 20^{\mathrm{c}}$} & \multicolumn{2}{|l|}{$\mathrm{BC} 40^{\mathrm{d}}$} & \multicolumn{2}{|l|}{ NR } & \multicolumn{2}{|l|}{$\mathrm{R}$} & \multicolumn{2}{|l|}{$\mathrm{BC} 20$} & \multicolumn{2}{|l|}{$\mathrm{BC} 40$} \\
\hline & & 540.0 & (24.7) & 747.5 & $(22.2)$ & 747.1 & $(26.5)$ & 646.8 & (15.9) & 58.9 & (1.1) & 57.3 & (7.0) & 79.7 & $(0.8)$ & 85.4 & (6.9) \\
\hline & $D_{\min } / \mu \mathrm{m}$ & 9.4 & $(0.4)$ & 10.9 & $(0.4)$ & 13.3 & $(0.5)$ & 13.5 & $(0.4)$ & 4.7 & $(1.6)$ & 2.4 & $(0.0)$ & 2.0 & $(0.6)$ & 0.8 & $(0.0)$ \\
\hline & $a$ & 0.006 & $5(0.001)$ & 0.007 & $(0.001)$ & 0.009 & $(0.001)$ & 0.007 & $(<0.0005)$ & 0.005 & $(<0.0005)$ & 0.006 & $(<0.0005)$ & 0.007 & $(<0.0005)$ & 0.008 & $(0.0005)$ \\
\hline & $b$ & 1.51 & $(0.14)$ & 1.40 & $(0.07)$ & 1.49 & $(0.10)$ & 1.48 & $(0.07)$ & 0.93 & $(0.006)$ & 0.95 & $(0.01)$ & 0.97 & $(0.02)$ & 0.99 & $(0.01)$ \\
\hline \multirow[t]{4}{*}{ Eth } & $D_{\max } / \mu \mathrm{m}$ & 692.9 & (16.8) & 670.8 & (15.1) & 741.8 & (17.0) & 712.5 & (13.6) & 88.8 & (4.6) & 99.1 & $(3.7)$ & 116.5 & $(6.1)$ & 163.0 & $(4.9)$ \\
\hline & $D_{\min } / \mu \mathrm{m}$ & 12.0 & $(0.4)$ & 12.8 & $(0.4)$ & 13.1 & $(0.8)$ & 13.5 & $(0.3)$ & 3.5 & $(0.0)$ & 2.7 & $(0.0)$ & 2.4 & $(0.0)$ & 3.5 & $(0.0)$ \\
\hline & $a$ & 0.008 & $3(0.001)$ & 0.006 & $(<0.0005)$ & 0.004 & $(<0.0005)$ & 0.005 & $(<0.0005)$ & 0.021 & $(0.001)$ & 0.021 & $(<0.0005)$ & 0.010 & $(<0.0005)$ & 0.032 & $(0.001)$ \\
\hline & $b$ & 1.35 & $(0.04)$ & 1.42 & $(0.05)$ & 1.97 & $(0.19)$ & 1.62 & $(0.08)$ & 0.96 & $(0.00)$ & 0.97 & $(0.00)$ & 0.74 & $(0.00)$ & 0.97 & $(0.00)$ \\
\hline \multirow[t]{4}{*}{ Benz } & $D_{\max } / \mu \mathrm{m}$ & 275.5 & (23.6) & 521.1 & (18.0) & 415.7 & $(26.8)$ & 283.4 & (81.9) & 37.8 & $(5.6)$ & 40.0 & $(5.5)$ & 49.5 & $(5.8)$ & 53.6 & (7.6) \\
\hline & $D_{\min } / \mu \mathrm{m}$ & 7.1 & $(1.2)$ & 11.6 & $(0.5)$ & 10.9 & $(1.2)$ & 9.6 & (1.9) & 0.1 & $(0.0)$ & 0.5 & $(0.0)$ & 1.5 & $(0.0)$ & 0.8 & $(0.0)$ \\
\hline & $a$ & 0.004 & $4(0.001)$ & 0.005 & $(0.001)$ & 0.005 & $(0.001)$ & 0.004 & $(0.002)$ & 0.004 & $(<0.0005)$ & 0.005 & $(<0.0005)$ & 0.006 & $(<0.0005)$ & 0.007 & $(<0.0005)$ \\
\hline & $b$ & 1.37 & $(0.19)$ & 1.54 & $(0.12)$ & 1.42 & $(0.16)$ & 1.35 & $(0.20)$ & 1.05 & $(0.01)$ & 0.99 & $(0.01)$ & 0.97 & $(0.00)$ & 0.99 & $(0.01)$ \\
\hline
\end{tabular}

${ }^{\mathrm{a} N R}$, no crop residue incorporation or biochar addition.

${ }^{\mathrm{b}} \mathrm{R}$, crop residue incorporation.

${ }^{\mathrm{c}} \mathrm{BC} 20$, biochar addition $\left(20 \mathrm{Mg} \mathrm{ha}^{-1}\right)$.

${ }^{\mathrm{d}} \mathrm{BC} 40$, biochar addition $\left(40 \mathrm{Mg} \mathrm{ha}^{-1}\right)$. 
experiment and then reached a plateau that might have indicated the presence of small aggregates $(c .15 \mu \mathrm{m})$ with strong resistance to disaggregation. Sandy loam aggregates showed constant disruption that slowed down after only $1000 \mathrm{~s}$ of analysis. The differences in soil behaviour might be attributable to the different sizes of aggregates subjected to laser analyses. Clay aggregate diameters ranged from $c .800$ to $10 \mu \mathrm{m}$ and included the structural dynamics of both macro- $(>250 \mu \mathrm{m})$ and microaggregate $(<250 \mu \mathrm{m})$ stability (Tisdall \& Oades, 1982). In contrast, sandy loam disaggregation kinetics were limited to microaggregates (on average, 80-1 $\mu \mathrm{m}$ ) because the macroaggregates had already been destroyed during fast wetting.

The mechanical cohesion of aggregate particles was observed mainly at low stress energy levels (i.e. large $D_{\max }$ ) and was followed successively by fast rates of disaggregation at high stress energy levels (i.e. large $a$ ). Consequently, an increase in the number of active surfaces (from biochar) prone to form stable complexes with either mineral or other organic molecules probably resulted as an effect of weak electrostatic interactions between soil particles. According to Fungo et al. (2017), biochar could be partially stored as free particulate organic carbon, and thereby show limited capacity for strong interactions with soil particles after short-term addition. Finally, the contribution of hydrophobicity to aggregate stability was negligible; no differences between treatments were observed. However, soils with small SOC content, in particular about $10 \mathrm{mg} \mathrm{kg}^{-1}$, had very variable contact angle measurements that depended on the spatial orientations of carbon compounds and functional groups towards the mineral surfaces (Bachmann et al., 2008). This suggests that a hydrophobic effect of biochar to increase aggregate stability should not be completely excluded.

\section{Conclusions}

Crop residues and biochar behaved differently in the dynamics of aggregate stability. Crop residue incorporation induced small incremental increases in the SOC of sandy loam soil. Our results suggest that SOC accumulation in short-term trials cannot produce a measurable effect from crop residues. However, there was some increase in wet aggregate stability, but that depended on soil type and amounts of crop residue. Contrasting effects on aggregate stability from biochar also depended on amounts applied and soil type. Two main mechanisms might explain this phenomenon: (i) in naturally clay-poor soil, the increase in soil surface area from biochar provides additional interparticle bonding, (ii) in clay-rich soil, some repulsive forces between particles with the same charge and excess monovalent cations increased soil dispersion. There was a change in pore-size distribution with biochar amendment towards smaller pores, especially in clay aggregates. Despite the use of biochar in agricultural soils to improve soil fertility, specific information on biochar amounts and type is needed to avoid disaggregation that might arise in clay-rich soil. Further investigations are needed to define site-specific management guidelines that increase SOC and enhance aggregate stability.

\section{Acknowledgements}

This research received funding from the European Union Seventh Framework Programme (FP7/2007-2013) under grant agreement no 603498 (RECARE project). We especially thank Mr Gianfranco Filippini of DipSA, Unibo, for preparation of the soil samples for SEM observation.

\section{References}

Ajayi, A.E., Holthusen, D. \& Horn, R. 2016. Changes in microstructural behaviour and hydraulic functions of biochar amended soils. Soil \& Tillage Research, 155, 166-175.

Andrenelli, M.C., Maienza, A., Genesio, L., Miglietta, F., Pellegrini, S., Vaccari, F.P. et al. 2016. Field application of pelletized biochar: short term effect on the hydrological properties of a silty clay loam soil. Agricultural Water Management, 163, 190-196.

Bachmann, J., Guggenberger, G., Baumgartl, T., Ellerbrock, R.H. \& Urbanek, E. 2008. Physical carbon-sequestration mechanisms under special consideration of soil wettability. Journal of Plant Nutrition and Soil Science, 171, 14-26.

Blanco-Canqui, H. 2017. Biochar and soil physical properties. Soil Science Society of America Journal, 81, 687-711.

Bieganowski, A., Ryżak, M. \& Witkowska-Walczak, B. 2010. Determination of soil aggregate disintegration dynamics using laser diffraction. Clay Minerals, 45, 23-34.

Bocchi, S., Confalonieri, R., Frigeni, S., Morari, F. \& Patruno, A. 2008. Wet aggregate stability index: precision assessment of Tiulin method trough an inter-laboratory test. Agrochimica, 52, 71-82.

Burrell, L.D., Zehetner, F., Rampazzo, N., Wimmer, B. \& Soja, G. 2016. Long-term effects of biochar on soil physical properties. Geoderma, 282, 96-102.

Cameron, K.C. \& Buchan, G.D. 2006. Porosity and pore-size distribution. In: Encyclopedia of Soil Science (ed. R. Lal), pp. 1350-1353. CRC Press, Boca Raton, FL.

Dal Ferro, N., Berti, A., Francioso, O., Ferrari, E., Matthews, G.P. \& Morari, F. 2012. Investigating the effects of wettability and pore size distribution on aggregate stability: the role of soil organic matter and the humic fraction. European Journal of Soil Science, 63, 152-164.

Dexter, A.R. 1985. Shapes of aggregates from tilled layers of some Dutch and Australian soils. Geoderma, 35, 91-107.

Diaz-Zorita, M., Perfect, E. \& Grove, J.H. 2002. Disruptive methods for assessing soil structure. Soil \& Tillage Research, 2, 155-175.

Fajardo, M., McBratney, A.M., Field, D.J. \& Minasny, B. 2016. Soil slaking assessment using image recognition. Soil \& Tillage Research, 163, 119-129.

FAO-UNESCO 2008. Soil Map of the World. Revised Legend. FAO, Rome.

Fungo, B., Lehmann, J., Kalbitz, K., Thiongo, M., Okeyo, I., Tenywa, M. et al. 2017. Aggregate size distribution in a biochar-amended tropical Ultisol under conventional hand-hoe tillage. Soil \& Tillage Research, 165, 190-197.

Glaser, B., Lehman, J. \& Zech, W. 2002. Ameliorating physical and chemical properties of highly weathered soils in the tropics with charcoal-a review. Biology and Fertility of Soils, 35, 219-230.

Herath, H.M.S.K., Camps-Arbestain, M. \& Hedley, M. 2013. Effect of biochar on soil physical properties in two contrasting soils: an Alfisol and an Andisol. Geoderma, 209-210, 188-197.

Jien, S. \& Wang, C. 2013. Effects of biochar on soil properties and erosion potential in a highly weathered soil. Catena, 110, 225-233. 
Kumari, K.G.I.D., Moldrup, P., Paradelo, M., Elsgaard, L. \& de Jonge, L.W. 2017. Effects of biochar on dispersibility of colloids in agricutlural soils. Journal of Environmemntal Quality, 46, 143-152.

Le Bissonnais, Y. 1996. Aggregate stability and assessment of soil crustability and erodibility : I. Theory and methodology. European Journal of Soil Science, 47, 425-437.

Lehmann, J. \& Kleber, M. 2015. The contentious nature of soil organic matter. Nature, 528, 60-68.

Lipiec, J., Siczek, A., Sochan, A. \& Bieganowski, A. 2016. Effect of sand grain shape on root and shoot growth of wheat seedlings. Geoderma, $\mathbf{2 6 5}$, $1-5$.

Ojeda, G., Mattana, S., Àvila, A., Alcañiz, J.M., Volkmann, M. \& Bachmann, J. 2015. Are soil-water functions affected by biochar application? Geoderma, 249-250, 1-11.

Ouyang, L., Wang, F., Tang, J., Yu, L. \& Zhang, R. 2013. Effects of biochar amendment on soil aggregates and hydraulic properties. Journal of Soil Science and Plant Nutrition, 13, 991-1002.

Peng, X., Ye, L.L., Wang, C.H., Zhou, H. \& Sun, B. 2011. Temperature-and duration-dependent rice straw-derived biochar: characteristics and its effects on soil properties of an Ultisol in southern China. Soil \& Tillage Research, 112, 159-166.

Pituello, C., Francioso, O., Simonetti, G., Pisi, A., Torreggiani, A., Berti, A. et al. 2015. Characterization of chemical-physical, structural and morphological properties of biochars from biowastes produced at different temperatures. Journal of Soils and Sediments, 15, 792-804.

Pituello, C., Polese, R., Morari, F. \& Berti, A. 2016a. Outcomes from a long-term study on crop residue effects on plant yield and nitrogen use efficiency in contrasting soils. European Journal of Agronomy, 77, $179-187$.

Pituello, C., Dal Ferro, N., Simonetti, G., Berti, A. \& Morari, F. 2016b. Nano to macro pore structuree changes induced by long-term residue management in three different soils. Agriculture, Ecosystems \& Environment 217, 49-58

Powlson, D.S., Glendining, M.J., Coleman, K. \& Whitmore, A.P. 2011. Implications for soil properties of removing cereal straw: results from long-term studies. Agronomy Journal, 103, 279-287.

Rawlins, B.G., Wragg, J. \& Lark, R.M. 2013. Application of a novel method for soil aggregate stability measurement by laser granulometry with sonication. European Journal of Soil Science, 64, $92-103$.
Schabenberger, O. \& Pierce, F.J. 2002. Contemporary Statistical Models for the Plant and Soil Sciences. CRC Press, Boca Raton, FL.

Schmidt, M.W.I., Torn, S., Abiven, S., Dittmar, T., Guggenberger, G., Janssens, A.I. et al. 2011. Persistence of soil organic matter as an ecosystem property. Nature, 478, 49-56.

Seta, A.K. \& Karathanasis, A.D. 1997. Stability and transportability of water-dispersible soil colloids. Soil Science Society of America Journal, 61, 604-611.

Siebold, A., Walliser, A., Nardin, M., Oppliger, M. \& Schultz, J. 1997. Capillary rise for thermodynamic characterization of solid particle surface. Journal of Colloid and Interface Science, 186, 60-70.

Six, J. \& Paustian, K. 2014. Aggregate-associated soil organic matter as an ecosystem property and a measurement tool. Soil Biology \& Biochemistry, 68, A4-A9.

Sun, F. \& Lu, S. 2014. Biochars improve aggregate stability, water retention, and pore-space properties of clayey soil. Journal of Plant Nutrition and Soil Science, 177, 26-33.

Tisdall, J.M. \& Oades, J. 1982. Organic matter and water-stable aggregates in soils. Journal of Soil Science, 33, 141-163.

Walkley, A. \& Black, I.A. 1934. An examination of the Degtjareff method for determining soil organic matter, and a proposed modification of the chromic acid titration method. Soil Science, 37, 29-38.

Wang, D., Fonte, S.J., Parikh, S.J., Six, J. \& Scow, K.M. 2017. Biochar additions can enhance soil structure and the physical stabilization of $\mathrm{C}$ aggregates. Geoderma, 303, 110-117.

Wang, J.G., Li, Z.X., Cai, C.F. \& Ma, R.M. 2014. Particle size and shape variation of Ultisol aggregates affected by abrasion under different transport distances in overland flow. Catena, 123, 153-162.

Wang, J., Xiong, Z. \& Kuzyakov, Y. 2016. Biochar stability in soil: meta-analysis of decomposition and poriming effects. Global Change Biology Bioenergy, 8, 512-523.

$\mathrm{Xu}, \mathrm{R}$. 2002. Electrophoretic light scattering-zeta potential measurement In: Particle Characterization: Light Scattering Methods (ed. B. Scarlett), pp. 289-343. Kluwer Academic, Dordecht.

Yu, X., Wu, C., Fu, Y., Brookes, P.C. \& Lu, S. 2016. Three-dimensional pore structure and carbon distribution of macroaggregates in biochar-amended soil. European Journal of Soil Science, 67, 109-120.

Zaher, H., Caron, J. \& Ouaki, B. 2005. Modeling aggregate internal pressure evolution following immersion to quantify mechanisms of structural stability. Soil Science Society of America Journal, 69, 12. 